\title{
The European Marine Observation and Data Network (EMODnet): Visions and Roles of the Gateway to Marine Data in Europe
}

\section{OPEN ACCESS}

Edited by:

Sabrina Speich,

École Normale Supérieure, France

Reviewed by:

Johannes Karstensen

GEOMAR Helmholtz Center for Ocean

Research Kiel, Germany

Pierre Yves Le Traon,

Mercator Ocean, France

Juliet Hermes,

South African Environmental

Observation Network, South Africa

*Correspondence: Belén Martín Míguez bmiguez@gmail.com

Specialty section: This article was submitted to

Ocean Observation,

a section of the journal Frontiers in Marine Science

Received: 31 October 2018 Accepted: 27 May 2019

Published: 12 July 2019

Citation:

Martín Miguez B, Novellino A, Vinci M,

Claus S, Calewaert J-B, Vallius $H$, Schmitt T, Pititto A, Giorgetti A, Askew

$N$, lona S, Schaap D, Pinardi N, Harpham Q, Kater BJ, Populus J, She J, Palazov AV, McMeel O, Oset P, Lear $D$, Manzella GMR, Gorringe $P$, Simoncelli S, Larkin K, Holdsworth N,

Arvanitidis $C D$, Molina Jack $M E$ Chaves Montero MM, Herman PMJ and Hernandez $F$ (2019) The

European Marine Observation and Data Network (EMODnet): Visions and

Roles of the Gateway to Marine Data in Europe. Front. Mar. Sci. 6:313. doi: 10.3389/fmars.2019.00313

\author{
Belén Martín Míguez ${ }^{1 *}$, Antonio Novellino ${ }^{2}$, Matteo Vinci ${ }^{3}$, Simon Claus ${ }^{4}$, \\ Jan-Bart Calewaert ${ }^{5,6}$, Henry Vallius ${ }^{7}$, Thierry Schmitt ${ }^{8}$, Alessandro Pititto ${ }^{9}$, \\ Alessandra Giorgetti ${ }^{3}$, Natalie Askew ${ }^{10}$, Sissy lona ${ }^{11}$, Dick Schaap ${ }^{12}$, Nadia Pinardi ${ }^{13}$, \\ Quillon Harpham ${ }^{14}$, Belinda J. Kater ${ }^{15}$, Jacques Populus ${ }^{16}$, Jun She ${ }^{17}$, \\ Atanas Vasilev Palazov ${ }^{18}$, Oonagh McMeel ${ }^{5,6}$, Paula Oset ${ }^{4}$, Dan Lear ${ }^{19}$, \\ Giuseppe M. R. Manzella ${ }^{2}$, Patrick Gorringe ${ }^{20}$, Simona Simoncelli ${ }^{21}$, Kate Larkin ${ }^{5,6,22}$, \\ Neil Holdsworth ${ }^{23}$, Christos Dimitrios Arvanitidis ${ }^{11}$, Maria Eugenia Molina Jack ${ }^{3}$, \\ Maria del Mar Chaves Montero ${ }^{3}$, Peter M. J. Herman ${ }^{24}$ and Francisco Hernandez ${ }^{4}$
}

\begin{abstract}
${ }^{1}$ Centro Tecnológico del Mar, Vigo, Spain, ${ }^{2}$ ETT S.p.A, Genova, Italy, ${ }^{3}$ Department of Oceanography Division (OCE), Istituto Nazionale di Oceanografia e di Geofisica Sperimentale (OGS), Trieste, Italy, ${ }^{4}$ Data Center, Flanders Marine Institute, Ostend, Belgium, ${ }^{5}$ Seascape Belgium, Brussels, Belgium, ${ }^{6}$ European Marine Observation and Data Network (EMODnet) Secretariat, Ostend, Belgium, ${ }^{7}$ Geological Survey of Finland, Espoo, Finland, ${ }^{8}$ Naval Hydrographic and Oceanographic Service, Brest, France, ${ }^{9}$ Cogea s.r.l. - Business Management Consultants, Rome, Italy, ${ }^{10}$ Joint Nature Conservation Committee, Peterborough, United Kingdom, ${ }^{11}$ Hellenic Centre for Marine Research, Anavyssos, Greece, ${ }^{12}$ Maris BV, Voorburg, Netherlands, ${ }^{13}$ Department of Physics and Astronomy, University of Bologna, Bologna, Italy, ${ }^{14} \mathrm{HR}$ Wallingford, Wallingford, United Kingdom, ${ }^{15}$ Arcadis N.V., Amsterdam, Netherlands, ${ }^{16}$ Institut Français de Recherche pour l'Exploitation de la Mer (IFREMER), Brest, France, ${ }^{17}$ Danish Meteorological Institute, Copenhagen, Denmark, ${ }^{18}$ Institute of Oceanology, Bulgarian Academy of Sciences, Varna, Bulgaria, ${ }^{19}$ Marine Biological Association of the United Kingdom, Plymouth, United Kingdom, ${ }^{20}$ Department of Core Services, Swedish Meteorological and Hydrological Institute, Norrköping, Sweden, ${ }^{21}$ Istituto Nazionale di Geofisica e Vulcanologia, Sezione di Bologna Dipartimento Ambiente, National Institute of Geophysics and Volcanology, Bologna, Italy, ${ }^{22}$ European Marine Board Secretariat, Ostend, Belgium, ${ }^{23}$ ICES, Copenhaguen, Denmark, ${ }^{24}$ Deltares, Delft, Netherlands
\end{abstract}

Marine data are needed for many purposes: for acquiring a better scientific understanding of the marine environment, but also, increasingly, as marine knowledge for decision making as well as developing products and services supporting economic growth. Data must be of sufficient quality to meet the specific users' needs. It must also be accessible in a timely manner. And yet, despite being critical, this timely access to known-quality data proves challenging. Europe's marine data have traditionally been collected by a myriad of entities with the result that much of our data are scattered throughout unconnected databases and repositories. Even when data are available, they are often not compatible, making the sharing of the information and data aggregation particularly challenging. In this paper, we present how the European Marine Observation and Data network (EMODnet) has developed over the last decade to tackle these issues. Today, EMODnet is comprised of more than 150 organizations which gather marine data, metadata, and data products and make them more easily accessible for a wider range of users. EMODnet currently consists of seven sub-portals: bathymetry, geology, physics, chemistry, biology, seabed habitats, and human activities. In addition, Sea-basin Checkpoints have been established to assess the observation capacity in the North Sea, Mediterranean, Atlantic, Baltic, Artic, and Black Sea. The Checkpoints identify whether the observation infrastructure in Europe 
meets the needs of users by undertaking a number of challenges. To complement this, a Data Ingestion Service has been set up to tackle the problem of the wealth of marine data that remain unavailable, by reaching out to data holders, explaining the benefits of sharing their data and offering a support service to assist them in releasing their data and making them available through EMODnet. The EMODnet Central Portal (www.emodnet. eu) provides a single point of access to these services, which are free to access and use. The strategic vision of EMODnet in the next decade is also presented, together with key focal areas toward a more user-oriented service, including EMODnet for business, internationalization for global users, and stakeholder engagement to connect the diverse communities across the marine knowledge value chain.

Keywords: EMODnet, data portal, open access, checkpoint, data services, marine knowledge, blue economy, data integrator

\section{INTRODUCTION}

Access to reliable and accurate ocean data and information is vital for addressing threats to the marine environment, for developing policies and legislation to monitor and protect vulnerable areas of our coasts and oceans, and in understanding trends and forecasting future changes. As highlighted in numerous reports and strategic documents produced by the European Commission (European Commission, 2010, 2012; EEA, 2015) better quality and more easily accessible marine data is a prerequisite for further sustainable economic development, or "blue growth". The potential of Europe's wealth of marine observations to support this growth is huge.

In this paper we will explain how the European Marine Observation and Data network (EMODnet) has evolved over the last decade improving access to marine data, metadata, and data products for a wider range of users. Shepherd (2018) explained the rationale behind the initiative, and its benefits for the blue economy. We will build on this and on Calewaert et al. (2016) (who first introduced EMODnet and highlighted some of its main features, including its thematic data portals) and will further present the remarkable progress achieved in the last years. We will first highlight the most recent developments of the thematic data portals, with a particular focus on three of them, -Physics, Chemistry, and Biology- to illustrate the concepts and multi-disciplinary nature of EMODnet. Furthermore, we will provide insights into how the other EMODnet strands (the Data Ingestion Service, the Sea-basin Checkpoints and the Central Portal) have greatly strengthened the service for users. The paper will also present the vision for EMODnet into the next decade, with renewed efforts toward engaging stakeholders to build a more user-oriented service with global relevance.

Abbreviations: API, Application Programme Interface; ASCII, American Standard Code for Information Interchange; BODC, British Oceanographic Data Centre; CDI, Common Data Index; CF, Climate and Forecast; CMEMS, Copernicus Marine Environment Monitoring Service; CPUE, Catch per Unit Effort; DATRAS, Database of Trawl Surveys; DBCP, Data Buoy Cooperation Panel; DCF, Data Collection Framework; DG GROW, Directorate-General for Internal Market, Industry, Entrepreneurship and SMEs; DG MARE, Directorate-General for Maritime Affairs and Fisheries; DG RTD, Directorate-General for Research and Innovation; DIS, Dissolved Inorganic Nitrogen; DIVA, Data-Interpolating

\section{THE CHALLENGE}

Ocean and marine data collection in Europe is carried out by hundreds of organizations in many different countries, working across a range of disciplines, and using heterogeneous observing

Variational Analysis; DOI, Digital Object Identifier; DTM, Digital Terrain Model; DwC, Darwin Core; EAS, European Atlas of the Seas; EC, European Commission; EEA, European Environment Agency; EGDI, European Geological Data Infrastructure; EGO, European Gliding Observatory; EMODnet, European Marine Observation and Data Network; EOV, Essential Ocean Variable; EU, European Union; EurOBIS, European Ocean Biogeographic Information System; GDAC, Global Assembly Data Centre; GEOSS, Global Earth Observation System of Systems; GES, Good Environmental Status; GLOSS, Global Sea Level Observing System; GMES, Global Monitoring for Environment and Security; GOOS, Global Ocean Observing System; GO-SHIP, Global Ocean Ship-based Hydrographic Investigation Programme; GPS, Global Positioning System; GROOM, Gliders for Research Ocean Observation and Management; HELCOM, Helsinki Commission; HF, High Frequency; HFR, High Frequency Radar; ICES, International Council for the Exploration of the Seas; IOG, Intergovernmental Oceanographic Commission; IODE, International Ocean and Data Exchange; IPT, Integrated Publishing Toolkit; ISO, International Standards Organization; JCOMMOPS, Joint Technical Commission of Oceanography and Marine Meteorology in situ Observing Platform Support Centre; JERICO, Joint European Research Infrastructure of Coastal Observatories; JRC, Joint Research Centre; JSON, JavaScript Object Notation; M2M, Machine to Machines; MAP, Mediterranean Action Plan; MCS, Marine Conservation Society; MEDITS, Mediterranean International Trawl Survey; MPA, Marine Protected Area; MSc, Master of Science; MSFD, Marine Strategy Framework Directive; MSP, Maritime Spatial Planning; NERC, Natural Environment Research Council; NetCDF, Network Common Data Format; NGO, Non-Governmental Organization; NODC, National Oceanographic Data Centre; NOAA, National Oceanic and Atmospheric Administration; NRT, Near Real Time; OBIS, Ocean Biogeographic Information System; ODV, Ocean Data View; OECD, Organization for Economic Co-operation and Development; OGC, Open Geospatial Consortium; OSPAR, Oslo-Paris (Convention); PhD, Philosophiae Doctor; PSMSL, Permanent Service for Mean Sea Level; QA, Quality Assurance; QC, Quality Control; REST, Representational State Transfer; ROOS, Regional Ocean Observing System; RTD, Research, Technology and Development; SMEs, Small and Medium Enterprises; SOAP, Simple Object Access Protocol; SOOS, Southern Ocean Observing System; SONEL, Systéme d'Observation du Niveau des Eaux Littorales; SWE, Sensor Web Enablement; TAC, Thematic Assembly Centre; THREDDS, Thematic Real-time Environmental Distributed Data; UNEP, United Nations Environment Programme; UNESCO, United Nations Educational, Scientific and Cultural Organization; WCS, Web Coverage Service; WFS, Web Feature Service; WMO, World Meteorological Organization; WMS, Web Map Service; WoRMS, World Register of Marine Species; WPS, Web Processing Service; XML, Exchange Markup Language. 
methods and sensors installed on board research vessels, underwater vehicles, fixed and drifting platforms, aircrafts, and satellites. Most data collection, by both private and public organizations, is carried out for a single, specific purpose, often in isolation from each other. Marine data can be generated as a result of marine environmental monitoring obligations, through the activities of maritime and offshore industries and by the research community. Increasingly data are also being generated by citizen science activities. All of these data may have numerous applications beyond the purpose for which they were taken. To anticipate this potential, great progress has already been made, with the development of standards, services, and infrastructures for providing long term storage and means of discovery and access to these valuable data resources. Activities have been undertaken as part of international initiatives, such as the International Ocean and Data Exchange (IODE) program of the Intergovernmental Oceanographic Commission (IOC) of UNESCO or the Working Group on Marine Data Management of the International Council for the Exploration of the Sea (ICES). In Europe, a series of projects have been dedicated to developing the pan-European SeaDataNet ${ }^{1}$ infrastructure, and the developments of the EurOBIS ${ }^{2}$ (marine biodiversity) and PANGAEA ${ }^{3}$ (marine earth science) data portals. However, for a variety of reasons, a large part of these data remained out of reach and thus inaccessible to other potential users, and European-scale cooperation between these data management initiatives was limited. This changed considerably with the launch of EMODnet in 2009, which aimed to establish an overarching European marine data and observation network. The establishment of EMODnet fostered coordination at European Union (EU) level between a number of EU directives and policies (Marine Strategy Framework Directive, Integrated Maritime Policy, Blue Growth) and largescale observation and data collection framework programs, such as the Global Monitoring for Environment and Security (GMES, now COPERNICUS ${ }^{4}$ ) and the Global Earth Observation System of Systems $\left(\right.$ GEOSS $\left.^{5}\right)$.

This is very much in line with one of the major challenges already identified in OceanObs09: the need for improved international and national organizational structures to build and sustain a truly interdisciplinary, coherent, systematic, sustained ocean observing system (Fischer et al., 2010). As we shall see, EMODnet is actively contributing to that endeavor.

\section{THE SOLUTION}

EMODnet is the key implementing mechanism of the European Commission's Marine Knowledge 2020 strategy (European Commission, 2010, 2012) to unlock the potential of Europe's wealth of marine data. Based on the principle of collecting data once and using it many times for many purposes, EMODnet is a

\footnotetext{
${ }^{1}$ https://www.seadatanet.org/

${ }^{2}$ http://www.eurobis.org/

${ }^{3}$ www.pangaea.de

${ }^{4}$ www.copernicus.eu

${ }^{5}$ https://www.earthobservations.org/geoss.php
}

network of organizations (currently more than 150) supported by the EU's Integrated Maritime Policy ${ }^{6}$ linked by a data management structure. These organizations work together to aggregate and process marine data from diverse sources and generate data products. EMODnet provides a gateway to those marine data accompanied by their metadata and data products through a number of thematic portals and a central portal ${ }^{7}$. As Shepherd (2018) outlines, EMODnet's objectives are to:

- Increase productivity in all tasks involving marine data by avoiding re-collection of data and saving costs involved in putting together marine data;

- Increase competition and innovation in established and emerging maritime sectors;

- Reduce uncertainty in our knowledge of the oceans and the seas and improve our ability to forecast the behavior of the seas.

\section{EMODnet DEVELOPMENT}

EMODnet's development is based on the following core principles that continue to guide and underpin the strategic expansion of its services:

- Collect data once and use them many times;

- Develop data standards across disciplines as well as within them;

- Process and validate data at different scales: regional, basin and pan-European;

- Build on existing efforts where data communities have already organized themselves;

- Put the user first when developing priorities and taking decisions;

- Provide statements on data ownership, accuracy, and precision;

- Sustainable funding at a European level to maximize benefit from the efforts of individual Member States;

- Free and unrestricted access to data and data products.

These core principles underpinning the development and operation of EMODnet are in alignment with the 2016 FAIR (Findable, Accessible, Interoperable, Re-usable) guiding principles for scientific data management and stewardship (Wilkinson et al., 2016).

Established in 2009, EMODnet is a long-term initiative that has been built through a phased approach (Table 1). During the first phase, six prototype data portals were developed. Largely building on existing data repositories, infrastructures, initiatives and projects by specific and distinct communities of experts, these covered a limited selection of sea-basins and parameters, and offered data-products at low resolution.

The second phase saw the data portals expanded to provide full coverage of all European sea-basins. A wider selection of parameters and medium resolution data products were also made

\footnotetext{
${ }^{6}$ The Integrated Maritime Policy has the objective to better coordinate Europe's maritime activities and the management of its marine environment https://ec. europa.eu/maritimeaffairs/policy_en

${ }^{7}$ www.emodnet.eu
} 
TABLE 1 | The three initial phases of EMODnet development up to 2020.

\begin{tabular}{lllllllll}
\hline $2009 \quad 2010 \quad 2011 \quad 2012$ & 2013 & 2014 & 2015 & 2016 & 2017 & 2018 & 2019 & 2020 \\
\hline Phase I-59 institutions, budget 6.5M Euros \\
- Prototype of thematic data portals \\
- Limited selection of parameters and sea-basins \\
- Low-resolution data products
\end{tabular}

Phase II-120 institutions, budget 16.3M Euros

- More parameters, and coverage (all sea-basins)

- Medium-resolution data products

- Human Activities portal, establishment of Central

Portal, Sea-basin Checkpoints, and Secretariat

\author{
Phase III-More than 150 institutions, \\ budget 20M Euros \\ - Multi-resolution digital map of entire \\ European seabed by 2020
}

available. The second phase also included the addition of a new portal on Human Activities and the creation of the cross-cutting EMODnet Central Portal, as well as the establishment of the six regional Sea-basin Checkpoints and the Data Ingestion facility. To oversee and coordinate these growing and diverse activities, an EMODnet Secretariat was also established.

Currently in its third development phase, EMODnet has reached a mature and operational stage where efforts are now focused on maximizing its use and achieving the goal of providing free access to a multi-resolution digital map of the entire European seabed by 2020.

Throughout the different phases, the number of institutions working together within EMODnet has grown from 59 in the first phase to currently more than 150 . The budget has also increased with time, having tripled from $6.5 \mathrm{M}$ Euros in the early years to $20 \mathrm{M}$ Euros in the current phase.

The development of EMODnet has not taken place in isolation. On the contrary, EMODnet has been built on and evolved in close connection with existing initiatives and infrastructures that are also part of the European and global marine data landscape, in particular, SeaDataNet and Copernicus Marine Service (CMEMS) (see Figure 1), which will be described briefly below.

After completion of the development phases, EMODnet will continue to develop beyond 2020 as a fully operational userfocused data service for society providing open and free access to marine data and data products that are interoperable with other key European and global data services (see section "EMODnet in the Next Decade").

\section{EMODnet THEMATIC GROUPS}

There are seven EMODnet thematic groups, which provide the data management infrastructure of EMODnet: Bathymetry, Geology, Seabed Habitats, Physics, Chemistry, Biology, and
Human Activities (see Table 2 for description of the thematic coverage provided by the portals ${ }^{8}$ ).

Although quite distinct in nature, each thematic group is underpinned by various data initiatives (data infrastructures, networks, projects, data assembly centers...) which, in turn, receive data from different data originators. EMODnet thematic groups build on those data initiatives and add value by (1) facilitating access to the data and (2) generating new products from them. EMODnet also provides friendly, user-oriented interfaces and services to guarantee an effective access to those data and data products.

Table 3 lists the main data initiatives, together with the ultimate data originators. For instance, the main pillar of the Geology thematic group is the European Geological Data Infrastructure $\left(\mathrm{EGDI}^{9}\right)$, while data originators are mostly geological surveys from across Europe. For Human Activities, data originators are very heterogeneous, both public (port authorities, ministries, European agencies...) and private (industrial clusters). Human Activities assembles data directly from them and not via any intermediary.

More differences are found in the data flow from the data originators to the provision of the data to the users amongst the different EMODnet thematic portals. This data flow comprises several steps including assembling, quality control (QC) and quality assurance (QA) (e.g., metadata curation, data standards compliance checks, control of geographic location, accuracy assessment) as well as harmonization/standardization (e.g., units, terminology, coordinate systems, data format...).

The relative importance of each of these steps and how they are performed (automatically, semi-automatically, or manually) and at what level (data originators, data initiative underpinning the thematic group, or the EMODnet thematic group partners themselves) depends on the thematic portal in question.

\footnotetext{
${ }^{8}$ More details about EMODnet data and data products can be found on http:// www.emodnet.eu/data-portfolio

${ }^{9} \mathrm{http}: / /$ www.europe-geology.eu/
} 


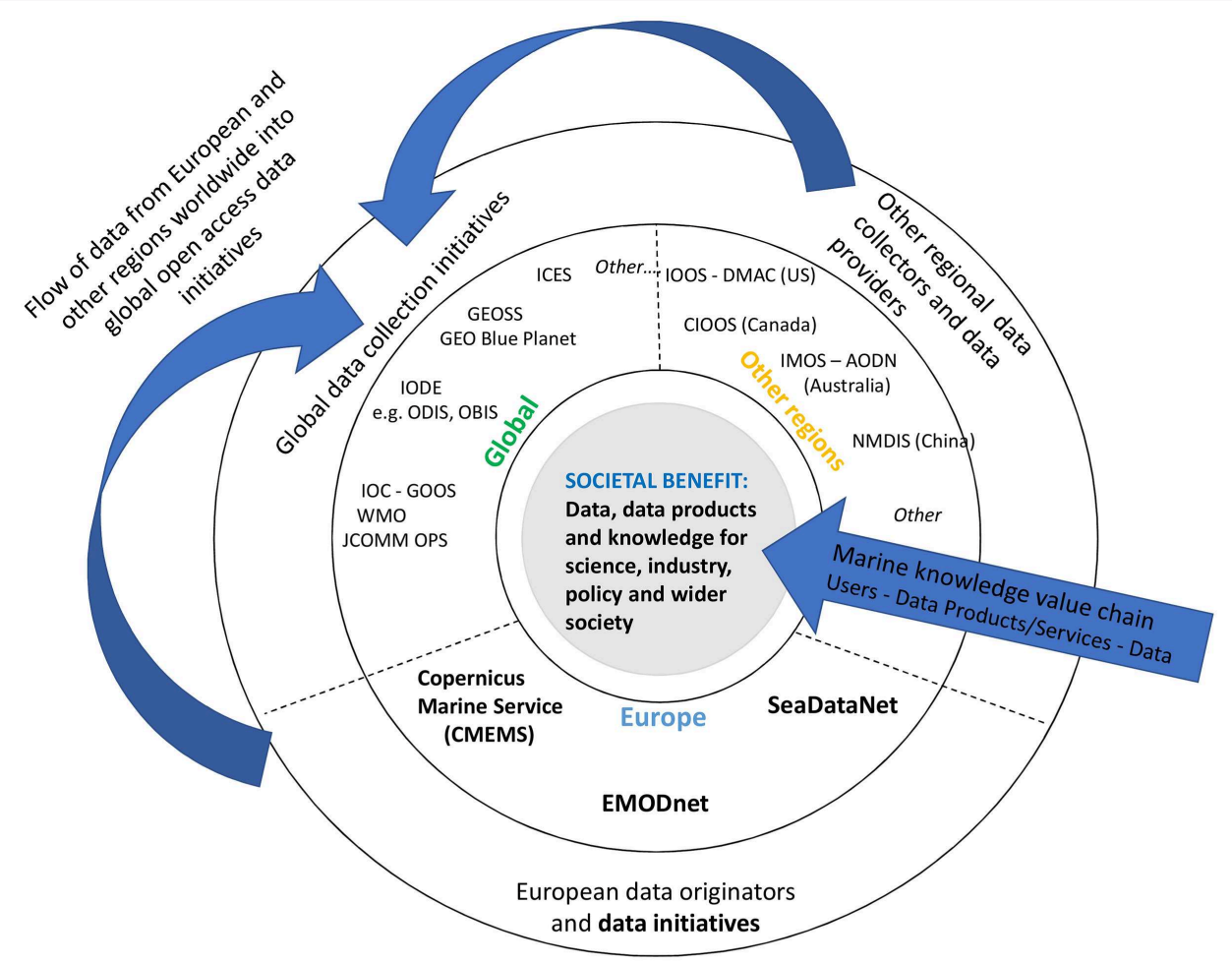

Explanation of key European open source data integrators and service providers, financed by the EU

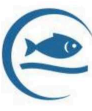

Copernicus

Marine Service

CMEMS is the operational marine service component of the COPERNICUS program and is funded by DG GROW (Directorate-General for Internal Market, Industry, Entrepreneurship and SMEs). It delivers generic and systematic information (observations and forecasts) on the physical state and dynamics of the ocean and marine ecosystems. CMEMS is composed by 3 main service layers: the central information, the dissemination unit and the production layers (composed by several production units that manage the production of observation and forecast products). One of the production units is the In Situ TAC - in situ thematic assembly centre - that is in charge of the collection and harmonization of near real time and delayed mode physical and biogeochemical oceanographic data. These data are used to feed models or to calibrate/validate the outcome of models of the others production units. The In Situ TACs also feed data into EMODnet Physics (see Section 6 for more details).

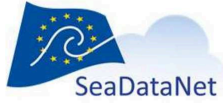

SeaDataNet is a pan-European data infrastructure for ocean and marine data management and is funded by DG RTD (Directorate-General for Research and Innovation). SeaDataNet community dates back to 1999 and was very much involved in the planning of EMODnet, now underpinning several EMODnet thematic groups: Chemistry, Bathymetry, Physics and to a lesser extent Biology. SeaDataNet data are derived from many different sensors installed on research vessels, satellites and in-situ platforms that are part of various ocean and marine observing systems and research programs. These different data are first assembled at distributed data centres interconnected by the SeaDataNet infrastructure. The data assembly centres are mostly National Oceanographic Data Centres (NODCs) which belong to major marine research institutes as well as international organizations such as IOC/IODE and ICES. These NODCs constitute an intermediate step between the data originators and SeaDataNet (see Table 2 and Section 6-7 for more details).

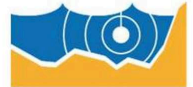

EMODnet is a long-term European initiative funded by DG MARE (Directorate-General for Maritime Affairs and Fisheries) that assembles and distributes marine data, metadata and data products spanning 7 thematic areas physics, bathymetry, geology, biology, chemistry, seabed habitat maps EMODnet and human activities (see other sections of this paper for further information).

FIGURE 1 | EMODnet in the context of other European, regional and global marine data, and data product initiatives. For Europe, only three pan-European initiatives supported long-term by the European Union are included. This list is not comprehensive but provides some key examples. The Figure shows the flow of marine knowledge from original data (outer circle) to data services (middle circle) and to the users and societal benefits (center). The Figure does not aim to define the wide variety of data collectors and data providers which span academia and public authorities to industry. Data collection networks, systems, and initiatives are also nation and region-specific. 
TABLE 2 | Thematic coverage provided by the data and products available through the EMODnet thematic portals.

\begin{tabular}{|c|c|c|c|c|c|c|}
\hline $\begin{array}{l}\text { - Digital Terrain } \\
\text { Model } \\
\text { - Survey tracks and } \\
\text { bathymetric survey } \\
\text { data } \\
\text { - Source references } \\
\text { - Depth contours }\end{array}$ & $\begin{array}{l}\text { - Seabed substrate } \\
\text { - Seabed } \\
\text { accumulation rates } \\
\text { - Seafloor lithology, } \\
\text { stratigraphy and } \\
\text { fault maps } \\
\text { - Coastal behavior } \\
\text { - Geological } \\
\text { events distributions } \\
\text { - Mineral } \\
\text { occurrences } \\
\text { - Submerged } \\
\text { landscapes } \\
\text { - Quaternary } \\
\text { geology* } \\
\text { - Geomorphology* } \\
\text { - Boreholes } \\
\text { locations* } \\
\text { - Seismic tracks }{ }^{\star} \\
\text { *Upcoming products }\end{array}$ & $\begin{array}{l}\text { Collection of point data } \\
\text { from surveys } \\
\text { - Broad-scale seabed } \\
\text { habitat map } \\
\text { - Environmental } \\
\text { variables influencing } \\
\text { habitat type } \\
\text { - Collection of } \\
\text { individual seabed } \\
\text { habitat maps from } \\
\text { surveys } \\
\text { - Modeled maps of } \\
\text { specific habitats } \\
\text { - Composite data } \\
\text { products } \\
\text { s }\end{array}$ & $\begin{array}{l}\text { - Wave height } \\
\text { and duration } \\
\text { - Sea temperature } \\
\text { - Wind speed } \\
\text { and direction } \\
\text { - Salinity } \\
\text { - Horizontal speed } \\
\text { of the } \\
\text { water column } \\
\text { - Water clarity } \\
\text { - Changes in sea level } \\
\text { - Inflow from rivers } \\
\text { - Water conductivity } \\
\text { /biochemical } \\
\text { parameters } \\
\text { - Atmospheric } \\
\text { parameters } \\
\text { - Underwater noise }\end{array}$ & $\begin{array}{l}\text { - Acidity } \\
\text { - Antifoulants } \\
\text { - Chlorophyll } \\
\text { - Dissolved gases } \\
\text { - Fertilizers } \\
\text { - Heavy metals } \\
\text { - Hydrocarbons } \\
\text { - Marine litter (micro, } \\
\text { beach, seafloor) } \\
\text { - Organic matter } \\
\text { - Pesticides and } \\
\text { biocides } \\
\text { - Polychlorinated } \\
\text { biphenyls } \\
\text { - Radionuclides } \\
\text { - Silicates }\end{array}$ & $\begin{array}{l}\text { - Phytoplankton } \\
\text { - Zooplankton } \\
\text { - Macro-algae } \\
\text { - Seagrass } \\
\text { - Fish } \\
\text { - Reptile } \\
\text { - Bird } \\
\text { - Sea mammals } \\
\text { - Benthos } \\
\text { - Functional traits } \\
\text { - Introduced species } \\
\text { - Protected species } \\
\text { - Indicator species }\end{array}$ & $\begin{array}{l}\text { - Aggregate extraction } \\
\text { - Algae production } \\
\text { - Aquaculture } \\
\text { - Cables } \\
\text { - Cultural heritage } \\
\text { - Dredging } \\
\text { - Environment } \\
\text { - Fisheries } \\
\text { - Hydrocarbon } \\
\text { extraction } \\
\text { - Main ports } \\
\text { - Ocean energy } \\
\text { facilities } \\
\text { - Other forms of } \\
\text { area management/ } \\
\text { designation } \\
\text { - Pipelines } \\
\text { - Waste disposal } \\
\text { - Vessel density } \\
\text { - Wind farms }\end{array}$ \\
\hline
\end{tabular}

Data products are free to access and use. In bold, data that match Essential Ocean Variables (EOVs).

TABLE 3 | Main data initiatives (networks, projects, data management infrastructures...) data assembly centers (in italics) and data originators underpinning each of the EMODnet portals in Europe.

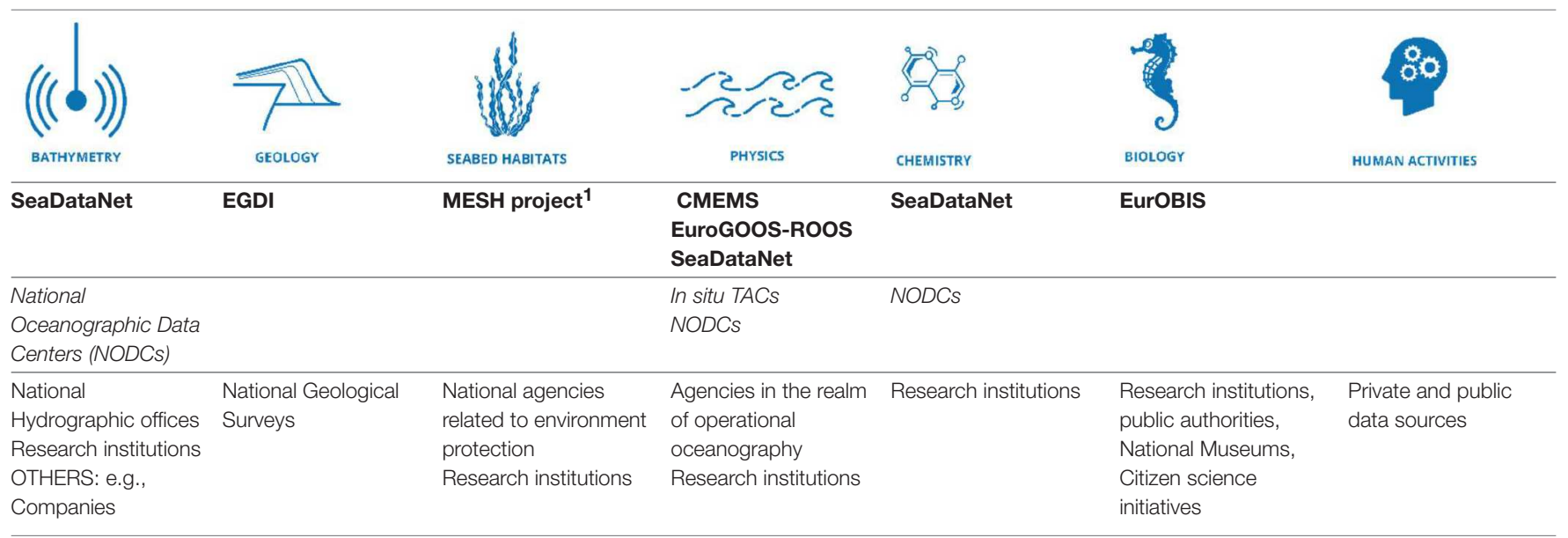

${ }^{1}$ MESH Project: a marine habitat mapping programme supported by the EU's INTERREG IIIB fund.

In addition, each EMODnet thematic group analyses and processes the data to create products: maps, animations, profiles, trends, and others. The ways in which they each do this can also be quite different. Ultimately, the user can find and access these data products (as well as the data and metadata) in the thematic portals, with each portal presenting specific features, tools, and services. In the next sections, we will describe in detail all these components of the knowledge value chain for three EMODnet thematic groups: Physics, Chemistry, and Biology. The reader is invited to visit the remaining thematic portals for additional information.

\section{EMODnet PHYSICS}

\section{Background}

EMODnet Physics originates from the advances made by the GOOS (Global Ocean Observing System) community (especially the European component, EuroGOOS) in the development of physical operational oceanography capabilities.

OceanObs99 had a vision of a "new era in oceanography, one where research and operational systems are mutually supportive and beneficial, and one where the rapid and wide distribution of information (data, methods and products) is 
accepted as preferred modus operandi" (Busalacchi, 2009). Twenty years later, in spite of technological advancements, data management, integration, and consistency remain a challenge.

Facing that challenge, EMODnet Physics has developed a "federated" network infrastructure and provides a single point of access to near real-time (NRT) and historical in situ datasets, products, and their metadata of physical parameters of European Seas and global oceans. This "federated" network infrastructure links data originators and other marine data aggregating infrastructures.

\section{Data Flow}

In Europe, EMODnet Physics is strongly federated with three other data aggregating infrastructures: (1) SeaDataNet and its network of National Oceanographic Data Centers (NODCs), (2) EuroGOOS-ROOS (Regional Operational Oceanographic Systems), and (3) the Copernicus Marine Environment Monitoring Service in situ Thematic Assembly Center (CMEMSin situ TAC). CMEMS-in situ TAC and EuroGOOS-ROOS are closely related and concern mostly the operational near real-time data flow, whereas NODCs provide historical validated data. EMODnet Physics is bridging the gap between both types of data streams.

SeaDataNet and CMEMS were described in Figure 1. EuroGOOS is an association of European agencies to further the goals of GOOS, and in particular the development of Operational Oceanography. EuroGOOS now has 42 members in 18 European countries. The EuroGOOS Regional Ocean Observing Systems (ROOS) are the core of the EuroGOOS association and are responsible for the collection of in situ data in the respective region. They feed near real-time data to both CMEMS and to EMODnet Physics. The CMEMS in situ TAC was developed on top of the EuroGOOS-ROOS concept and infrastructure.

EuroGOOS-ROOS, CMEMS-in situ TAC and SeaDataNetNODCs are also integrated with other available sources beyond Europe. In this way, EMODnet Physics interacts with international data collection networks and programmes like JCOMMOPS (the Joint Technical Commission of Oceanography and Marine Meteorology in situ Observing Platform Support Center), which supports several IOC and World Meteorological Organization (WMO) programmes.

The collaboration between EMODnet Physics and JCOMMOPS has largely increased the platforms and data connected to the portal since its initial phase in 2010. Datasets acquired under the umbrella of international programmes such as Argo, $\mathrm{DBCP}^{10}$ and GO-SHIP ${ }^{11}$, are monitored by JCOMMOPS and made accessible via EMODnet Physics.

EMODnet Physics database is updated three times a day. There are three main NRT pathways to EMODnet Physics. The first route is via the EuroGOOS ROOSs and the CMEMS in situ TAC. This combined infrastructure is based on regional nodes which guarantee the same quality of the products delivered to the end-user. The second route collects and distributes data

${ }^{10}$ Data Buoy Cooperation Panel http://www.jcommops.org/dbcp/

${ }^{11} \mathrm{http} / / /$ www.go-ship.org/ from international monitoring programs such as Argo, GO-SHIP, DBCP, etc., which are collected and organized by the Global Assembly Data Centers (GDAC). Data quality control is left to the responsibility of the data originators, who are required to use internationally agreed methods. The third route is via Thematic Assembly Centers (TACs) that are in charge for the collection and dissemination of "younger" platforms and parameters (e.g., sea surface currents fields recorded by HF Radars). For the three cases, operational platforms provide data time series as soon as data are ready-e.g., a fixed platform delivers data daily (at least), an Argo float delivers almost weekly.

Data transmitted in real time only undergo a "rough" quality control. They are provisionally included in the system, but eventually replaced by reprocessed data, submitted to a stricter quality control performed by NODCs. This replacement occurs periodically, but the time lag may vary depending on the type of platform/data network.

Dissemination of European historical validated data is organized in coordination and cooperation with SeaDataNet and the network of NODCs. The NRT data go through a stricter quality control before NODCs validate the datasets for longterm storage and stewardship. This validation process ends when the metadata of the processed dataset are published in a CDI (Common Data Index).

Moreover, EMODnet Physics portal provides data access toand preview of- coastal data in non-European areas (e.g., NOAA platforms for the US and globally, International Arctic Buoy Programme platforms for the Arctic area, the Integrated Marine Observing System for Australia and others) and it provides regional stakeholders and international networks with tools to serve their users and communities.

After 10 years, EMODnet Physics can now boast global coverage (Figure 2), by incorporating data from supplementary physical monitoring systems: drifting buoys, gliders, and emerging measurement systems (e.g., HF radar, animal borne instruments, etc.). In total, it provides access to more than 160,000 platforms, and more than 800,000 datasets. All available data and metadata follow the same standards (CF Convention and Metadata ${ }^{12}$ and SeaDataNet controlled vocabularies) and formats (e.g., NetCDF, csv).

\section{Products}

Besides data and metadata, EMODnet Physics also generates products that serve specific communities and stakeholders.

One example of EMODnet Physics products in collaboration with a Pan-European High-Frequency Radar Network (Rubio et al., 2017; Roarty et al., 2019) are sea-surface currents from high-frequency radars. Another example of a specific product under construction is river outflow, combining the geometry of the rivers, in situ data (very often water level and not water flux) and satellite observations.

Some products require collaboration with experts from different geographical regions. Since EMODnet Physics is federated with SeaDataNet and CMEMS, it can provide access to some of their products. For instance, SeaDataNet regional

\footnotetext{
${ }^{12} \mathrm{http}: / /$ cfconventions.org/
} 


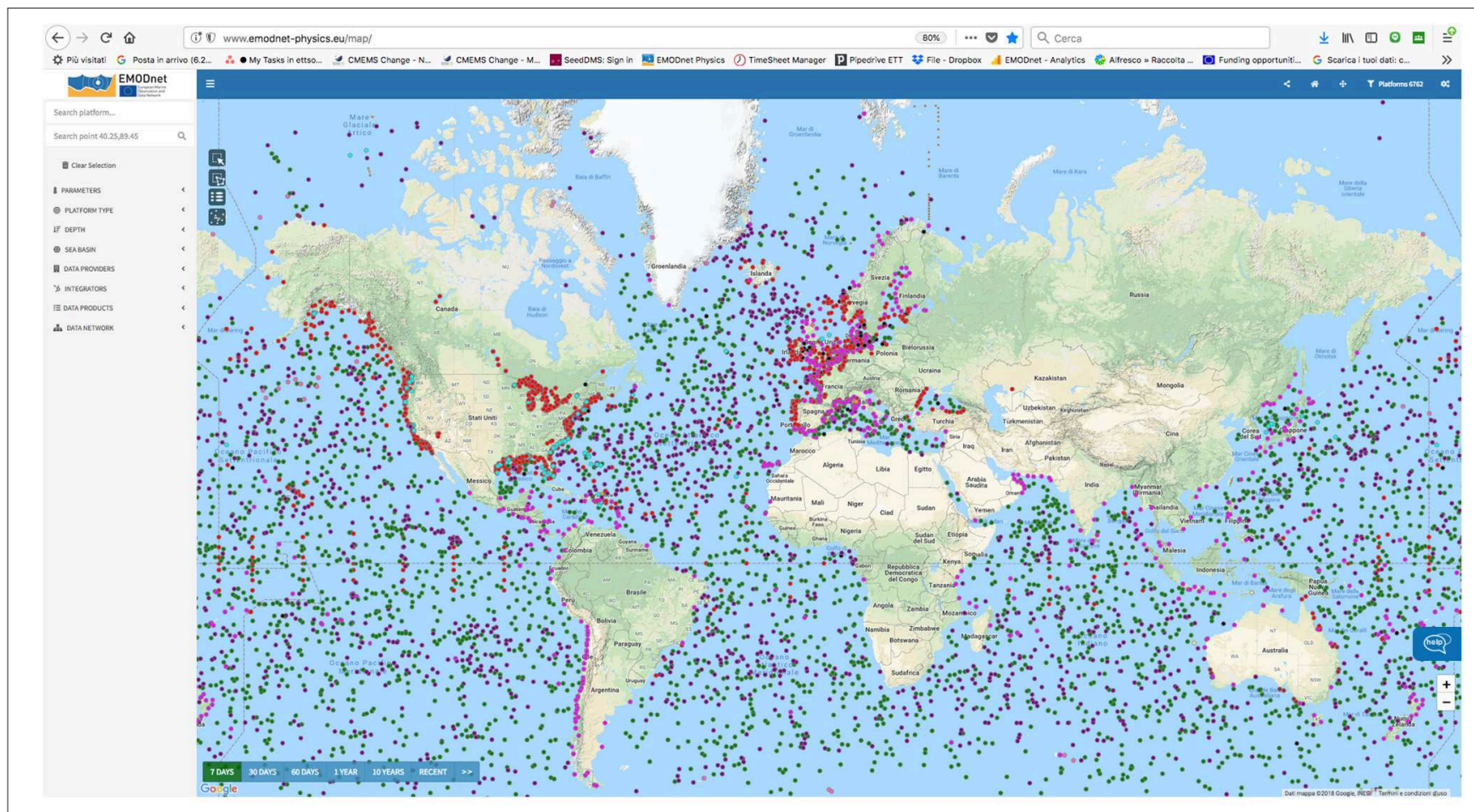

FIGURE 2 | 1Example of data accessible in EMODnet Physics during a 1 week period.

products such as temperature and salinity climatologies in the Arctic, Black Sea, Baltic Sea, the Mediterranean, North Sea, Atlantic-Iberian, and Biscay-Irish Sea are accessible through EMODnet Physics, with advanced sub-setting and discovering features. EMODnet Physics also provides access to gridded temperature and salinity from reprocessed data for the last century as well as ice coverage in the Arctic.

Another example concerns sea-level data and data products. By integrating more than 400 European tide gauge stations, 290 stations from the Global Sea Level Observing System (GLOSS) core network, and more than 1,300 stations from the Permanent Service for Mean Sea Level (PSMSL), EMODnet Physics is offering one of the widest in situ data collections for sea-level data. Based on the PSMSL collection, EMODnet Physics is making available maps of relative sea level trends, while absolute sea level maps are based on the SONEL product from the University of La Rochelle (France) ${ }^{13}$.

\section{Portal and Services}

EMODnet Physics is continuously increasing the number and type of platforms in the system by unlocking and providing data from a growing number of data sources. For each connected platform, a dedicated platform page is available that provides the user with metadata, plots, download features, platform products (e.g., monthly averages or wind plots), additional information and links, as well as statistics on the use of the data from that specific platform. Data quality information is available in connection to datasets.

EMODnet Physics is developing interoperability services (Table 4) to facilitate machine-to-machine interaction and to provide other systems and services with ocean physical data and metadata from the European seas. A way to pursue this is through the continuous systems' update with new interoperability services, techniques (Open Geospatial Consortium-OGC, Sensor Web Enablement-SWE) and standards (ISO, NetCDF, IODE), in particular:

- Fixed stations: NetCDF format, SeaDataNet vocabulary, CF (Climate and Forecast) convention variable

- Argo: NetCDF format, SeaDataNet vocabulary, CF convention variable

- Surface drifter: Standards and data management established by JCOMM/DBCP

- Deep ocean observatories: FixO3 data policy (based on OceanSITES policy), NetCDF format and ASCII;

- Glider: Standards and data management of the EGO COST Action ES0904 ${ }^{14}$ and FP7 GROOM

On top of these common standards, EMODnet Physics develops and provides a further level of interoperability tools such as Web Map Service (WMS), Web Feature Service (WFS), REST/Simple Object Access Protocol (SOAP) web

${ }^{13}$ www.sonel.org

$\overline{{ }^{14} \text { https://www.ego-network.org/dokuwiki/doku.php }}$ 
TABLE 4 | EMODnet physics interoperability machine to machine M2M services.

\begin{tabular}{lll}
\hline Service & Description & Examples \\
\hline PermaURL & All platforms & http://www.emodnet-physics.eu/map/platinfo/piradar.aspx?platformid=10273 \\
& & $\begin{array}{l}\text { http://www.emodnet-physics.eu/map/platinfo/pidashboard.aspx?platformid=10273 } \\
\text { Service description at: } \\
\text { http://www.emodnet-physics.eu/map/spi.aspx }\end{array}$ \\
API REST/SOAP & Latest 60 days of data & www.emodnet-physics.eu/map/Service/WSEmodnet2.aspx \\
OGS WMS, WFS, WCS & Postgresql + Geoserver & geoserver.emodnet-physics.eu/geoserver/web \\
& & $\begin{array}{l}\text { examples and service description at: } \\
\text { www.emodnet-physics.eu/map/service/GeoServerDefaultWMS.aspx }\end{array}$ \\
THREDDS (OpenDAP, WMS, WCS) & Latest 60 days + HFR data + Ice & www.emodnet-physics.eu/map/service/GeoServerDefaultWFS.aspx \\
thredds.emodnet-physics.eu/thredds/catalog.html & erddap.emodnet-physics.eu \\
ERDDAP & Latest 60 days & www.emodnet-physics.eu/Map/Charts/PlotDataTimeSeries.aspx? \\
Widgets & All plots & paramcode=TEMPplatid=8427timerange=7
\end{tabular}

services, THREDDS ${ }^{15}$, and ERDDAP ${ }^{16}$ catalogs, in order to make these data accessible, discoverable, and usable by a wider community. Interoperability services are provided by a GeoServer infrastructure that is OGC compliant. Plot widgets to embed a parameters plot/chart into an external portal are offered too.

To facilitate the use of the available services, documentation and details on available machine-to-machine interfaces are made available on github ${ }^{17}$.

Data and data products are accompanied by metadata covering information on ownership, data quality, and data quality check procedures, as well as links to get additional information on methods used for their constructions. Common QA/QC protocols as well as best practices have been collected and made available through the Physics portal ${ }^{18}$.

\section{EMODnet CHEMISTRY}

\section{Background}

EMODnet Chemistry's main purpose is to provide data and information relevant for the European Union's Marine Strategy Framework Directive (MSFD) (European Union, 2008), adopted in 2008 to set rules to protect more effectively the marine environment across Europe and to achieve Good Environmental Status (GES) by 2020. MSFD GES is defined by 11 qualitative Descriptors (and related criteria) that provide a detailed insight of the marine environmental status and its possible evolution. In addition, EMODnet Chemistry complies with the INSPIRE Directive (European Union, 2007/2/EC), which establishes rules for handling, accessing and sharing spatial information at European scale focusing on interoperability of spatial data sets and services.

EMODnet Chemistry places special focus on high-quality marine environmental data related to the MSFD GES

${ }^{15}$ THREDDS Catalogs are logical directories of on-line data resources, encoded as XML documents, which provide a place for annotations and other metadata.

${ }^{16}$ ERDDAP is a data server that provides a simple, consistent way to download subsets of scientific datasets in common file formats and make graphs and maps.

${ }^{17}$ https://github.com/EMODnet-Physics/EMODnet-Physics-Documentation

${ }^{18} \mathrm{http}: / /$ www.emodnet-physics.eu/portal/bibliography
Descriptor 5 (Human-induced eutrophication), Descriptor 8 (Concentrations of contaminants), Descriptor 9 (Contaminants in fish and other seafood), and Descriptor 10 (Marine litter) at a regional scale. The goal is to build a knowledge base to support the implementation of marine policies and foster sustainable development. Data relate to three matrixes (water column, sediment, and biota) and have recently extended to debris on beaches (nets, bottles etc.), on the seafloor (i.e., litter collected by fish-trawl surveys), and in the water column (floating micro-plastics).

EMODnet Chemistry is built upon SeaDataNet and its network of NODCs (see Figure 1; Table 3), adopting and adapting as necessary its standards, tools, and federated network of data resources.

\section{Data Flow}

The data flow within EMODnet Chemistry consists of a series of steps necessary to publish reliable and harmonized data and data products. The steps include, amongst others, assembly, quality control/quality assurance (QC/QA), and standardization. Interoperability and reliability are safeguarded through standardization and quality control procedures, carried out after data collection.

A network of NODCs distributed across many countries performs the data assembly. At the national level these NODCs supervise the provision of environmental data from research and monitoring activities, maintain regular contact with data originators, and complement data with the best available metadata to ensure reliability. The direct link with the data sources ensures that the best sets of measured data and associated metadata are stored with a commonly agreed data policy.

Data originators are responsible for the first quality control of data and flagging with quality information. Within EMODnet Chemistry, a data validation loop was developed to highlight possible data inconsistencies in the distributed infrastructure in close contact with data originators. As a first step of this loop, data are checked and completed with a standard set of metadata. A set of QC are applied to ensure e.g., that geographical position and time of data are realistic and to compare measurements with broad ranges and specific regional ranges. Whenever available, data are also compared with climatologies. As a result, all data 
are archived with a quality flag value that provides information on their reliability. Data are then aggregated at basin scale (grouping different analytic terms used by data originators into a unique aggregated term with a unique measurement unit) and further quality controls are performed at regional level following a common approach. The main goal of this activity is to obtain homogeneous regional datasets (e.g., a unique dataset of phosphate concentration in the water column starting from different datasets of phosphate concentration expressed with different units) that could be used to generate homogeneous data products. The results of the regional quality control are sent to the NODCs to correct errors or anomalies in the original copy of the data available in the EMODnet infrastructure. This feedback loop guarantees a continuous data quality upgrade.

Standardization is implemented at two main levels: syntactic and semantic. The former is achieved through provision of common formats for metadata and data files; the latter with the adoption of a set of vocabularies that become a common language to describe data and metadata over time, collected by diverse projects and in different countries. EMODnet Chemistry metadata are stored in the XML ISO 19139-19115 standard, and make use of a set of common vocabularies to ensure interoperability $^{19}$. Data are stored in Ocean Data View (ODV) format, a simple comma-separated value format including quality information for each parameter.

Once all those steps are accomplished, EMODnet Chemistry generates customized products and provides data sharing services in line with the policies defined by data originators. Products generation enables to analyze and re-aggregate data to build knowledge from raw data.

Data usage is managed according to the SeaDataNet Data Policy, which includes a range of access conditions from open access (SeaDataNet license) to negotiable. The latter is used by a small percentage of data originators in cases such as during a moratorium period, or when the data are especially costly (e.g., seismic survey data), or sensitive (e.g., contaminants in seafood data). Furthermore, the SeaDataNet Data Policy contains a disclaimer and an obligation for users to acknowledge data originators in their use cases. Thanks to the mutual trust between data originators and the NODCs, originators are increasingly willing to release their restricted datasets for use in the construction of EMODnet data products. At the same time, data originators are progressively encouraged to share their data more openly and under the SeaDataNet license.

Management of marine litter data is a recent addition to the infrastructure. The topics of interest are beach litter, seafloor litter and floating micro litter. In Europe, the development of the management systems for the three debris categories are different in terms of observation instruments, policies, and degree of development (regional, national...). The data management plan was to adopt consolidated data formats when available and adapt them when needed. Following this, three specific approaches have

\footnotetext{
${ }^{19}$ SeaDataNet DATA QUALITY CONTROL PROCEDURE https://www. seadatanet.org/content/download/596/3118/file/SeaDataNet_QC_procedures_ V2_(May_2010).pdf?version=1
}

been adopted, using the best available reference documents to develop a tailor-made approach at European scale.

For beach litter, the approach is based on the OSPAR (Convention for the Protection of the Marine Environment of the North-East Atlantic) experience and opens the possibility to report data using OSPAR, MSFD, UNEP (United Nations Environment Programme)/MAP (Mediterranean Action Plan), and UNEP Marlin (Baltic marine litter project Marlin-Litter monitoring and Raising awareness 2011-2013) categories.

For bottom trawl litter in Europe, there are two main consolidated data collection protocols since several years. One is adopted in the North/Western part of Europe -ICES DATRAS (Database of Trawl Surveys), while the other is adopted in the Mediterranean area [MEDITS (Mediterranean International Trawl Survey)/UNEP/MAP MED POL programme $\left.{ }^{20}\right]$. The EMODnet Chemistry approach followed the ICES DATRAS experience, but it is possible to report data using ICES, MSFD or MEDITS categories.

For floating marine micro-litter, the SeaDataNet formats (CDI and ODV) were adopted and adjusted following comparison with other available European information. Data collection for marine litter is done through already existing regional data bases (OSPAR/MCS for beach litter, ICES for bottom trawls) or through the network of NODCs.

\section{Products}

As stated earlier, EMODnet Chemistry has developed with the aim to become a major support tool for the assessment of marine environmental status under the MSFD. In addition to data, EMODnet Chemistry delivers data products related to MSFD Descriptor 5, 8, 9, and 10.

When developing European-scale products, comparability and harmonization of approaches must be assured, while respecting the peculiarities of each marine region. Regional and combined interpolated data maps are available based on DIVA 4D 10-year analysis. DIVA stands for Data-Interpolating Variational Analysis (Troupin et al., 2012). It is a software for spatial interpolation of in situ data to generate gridded fields, which uses an efficient finite-element method. DIVA works with a variational inverse methodology to derive a continuous field starting from discrete observations. DIVA basin maps have been developed only for nutrients with good data coverage (Figure 3). Considering that EU Member States must perform reporting under the MSFD on a 6 year cycle basis, new regional maps with a 6 year moving window are under development for the parameters silicate, phosphate, chlorophyll, oxygen, and Dissolved Inorganic Nitrogen (DIN).

Additionally, regional validated data collections for "eutrophication-related" parameters are being prepared and made available to the European Environmental Agency and to any other possible users.

For contaminants, spatial coverage is fragmented and there is a large heterogeneity in the data from monitoring. In 20182019, maps of contaminants have been generated and will be ${ }^{20}$ The MED POL programme is the marine pollution assessment and control
component of MAP. 


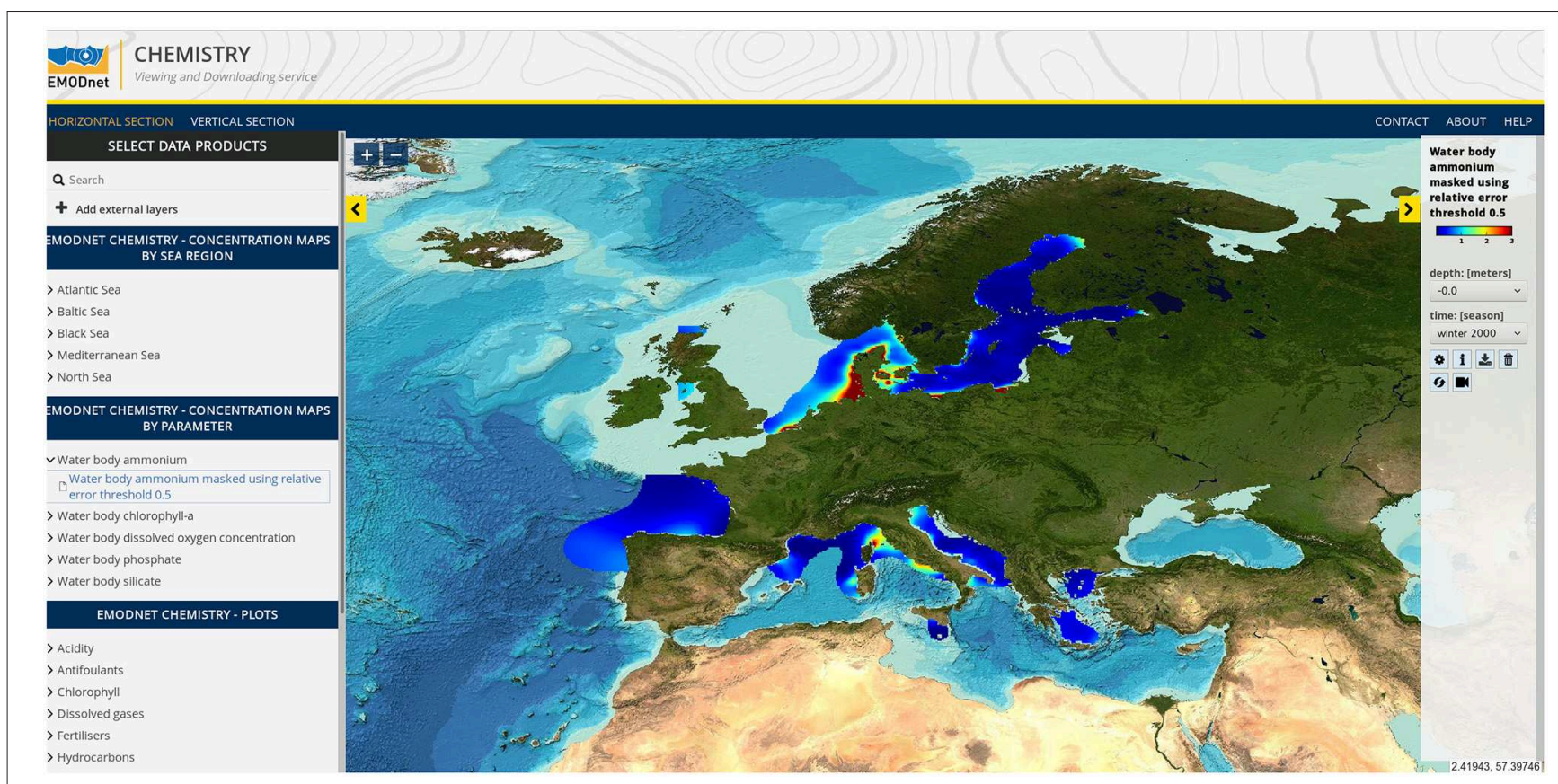

FIGURE 3 | Products: global interpolated maps for Ammonium in the water column, winter 2000.

presented to the board of experts for validation. Harmonized and aggregated data collections for the contaminants have been equally produced and will be available through the web portal in 2019.

Litter is a new topic for EMODnet Chemistry and so are its products. Litter data and their coding systems for quantification are very heterogeneous so their aggregation into products will be a challenge. First data analyses and basic outlines have been produced; even simple visualizations of a whole European dataset can be useful tools for managers. Maps of the surveys for beach and seafloor litter were published recently (March 2019). They highlight the differences between the litter reference lists and gears used along the European coasts (Figure 4).

Beyond 2019, the objective is to take advantage of the valuable information in a harmonized litter database to create a variety of products tailored to different stakeholder requirements.

\section{Portal and Services}

As for the other EMODnet portals, the EMODnet Chemistry portal $^{21}$ has dedicated services to access metadata, data, and products. Metadata and data are accessible through the CDI data access interface, while products are accessible using the viewing service (Ocean Browser) and the product catalog (Sextant). Metadata and products are always freely available.

- The CDI data access interface provides a service to search and browse what is available. There are several search criteria to filter out the available information (free text, parameter, spatial coverage, period covered, data originator, and others). A specific version of the interface named "Search Chemicals by Region" plots the regions of interest against the available parameters, so as to provide quicker access. Data are available in the following formats: ODV, NetCDF, or Medatlas. Registered users can freely access unrestricted data, while a negotiation process moderated by the relevant NODC is necessary for restricted data ${ }^{21}$.

- The Ocean Browser viewing service provides access to the available products. Products are provided in OGCcompliant formats (WMS, WFS, Web Processing Service WPS) to ensure interoperability. The product viewing service provides access to interpolated maps (WMS layers) and dynamic plots generated on the fly (WPS) from the validated data buffers.

- Sextant is a catalog compliant with OGC/Catalog Service Web (OGC/CSW) protocol and provides facilities to search and access the EMODnet Chemistry products (interpolated maps for each EU sea-basin, interpolated maps combining all the EU sea-basins, validated, aggregated, and harmonized data sets). All the available products are described and continuously updated in Sextant. Digital Object Identifiers (DOI) have been attributed to each of the products and the related landing pages have been published with download and viewing links.

- Furthermore, web portal hosts a page with detailed information on the available web services in order to facilitate M2M interaction $^{22}$.

$\overline{{ }^{21} \text { www.emodnet-chemistry.eu/data }}$

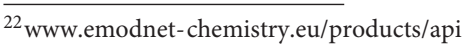




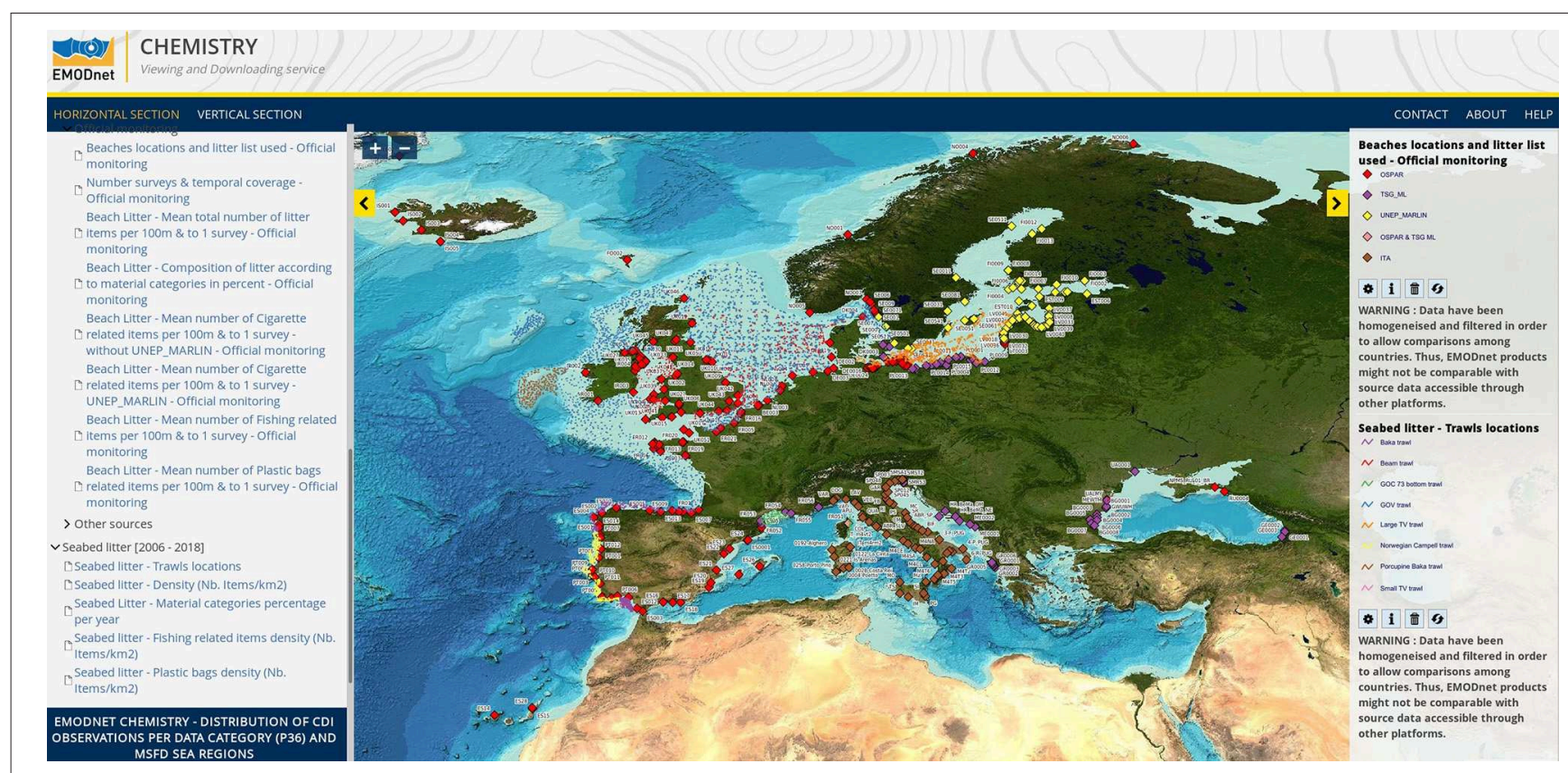

FIGURE 4 | Map showing the spatial distribution of the European surveyed beaches (monitoring sources) and European trawls locations highlighting the differences on the litter reference list and trawling gears used (March, 2019).

\section{EMODnet BIOLOGY}

\section{Background}

Marine biodiversity data are essential to measure and study the ecosystem health status of maritime basins and their trends in time. In the ocean, overfishing and other threats (such as pollution and eutrophication, climate change, habitat fragmentation, alien species, or mining activities) have reduced species' populations and have altered ecosystems, reducing their capacity to generate food resources and many other services for humankind. Furthermore, many species of mammals, birds, reptiles, and fish are in danger of extinction. In a time of global change and biodiversity loss, species observations over time are crucial for species inventories, as inputs to ecological models and for future predictions of change.

In marine biology, a large variety of methods have been used to sample marine species, including visual observations, water samples, nets, hooks, traps, grabs, sediment collection, acoustic observations or bio-optics. Various methods and metrics have been used to characterize the relative abundance of species, including numbers of individuals, surface cover, and/or biomass within samples. Furthermore, marine biodiversity data are often collected with limited spatial and temporal scope in small datasets for a specific species group or habitat and are scattered over different research institutes, governmental organizations and private companies in European and non-European countries bordering the European seas. Therefore, there is a continuous need to assemble these individual datasets, and process them into interoperable data formats for assessing the environmental state of overall ecosystems and complete sea-basins.

EMODnet Biology disseminates information about marine species in European waters including observations of phytoplankton, zooplankton, angiosperms, macro-algae, benthos, marine mammals, marine reptiles, birds, and fish. The project produces digital data products allowing analysis of changes in species abundance and extent over time and space. The taxonomic standard used in EMODnet Biology are based on the World Register of Marine Species (WoRMS), the authoritative and comprehensive global list of names of marine organisms. Geographical units are standardized to marineregions.org geo-objects and additional biotic or abiotic measurements are mapped using controlled thesaurus from the Natural Environment Research Council (NERC) Vocabulary Server maintained by the British Oceanographic Data Center (BODC). Through the implementation of the European Ocean Biogeographic Information System (EurOBIS) as marine biological data infrastructure of EMODnet Biology, data are processed following the Darwin Core Archive, an internationally recognized biodiversity informatics data standard that simplifies the publication of biodiversity data. EurOBIS has a strong collaboration with the Ocean Biogeographic Information System (OBIS), an evolving global strategic alliance of people and organizations sharing a vision to make marine biogeographic data, from all over the world, freely available over the World Wide Web. OBIS is the world's largest database on the diversity, distribution and abundance of marine life. 


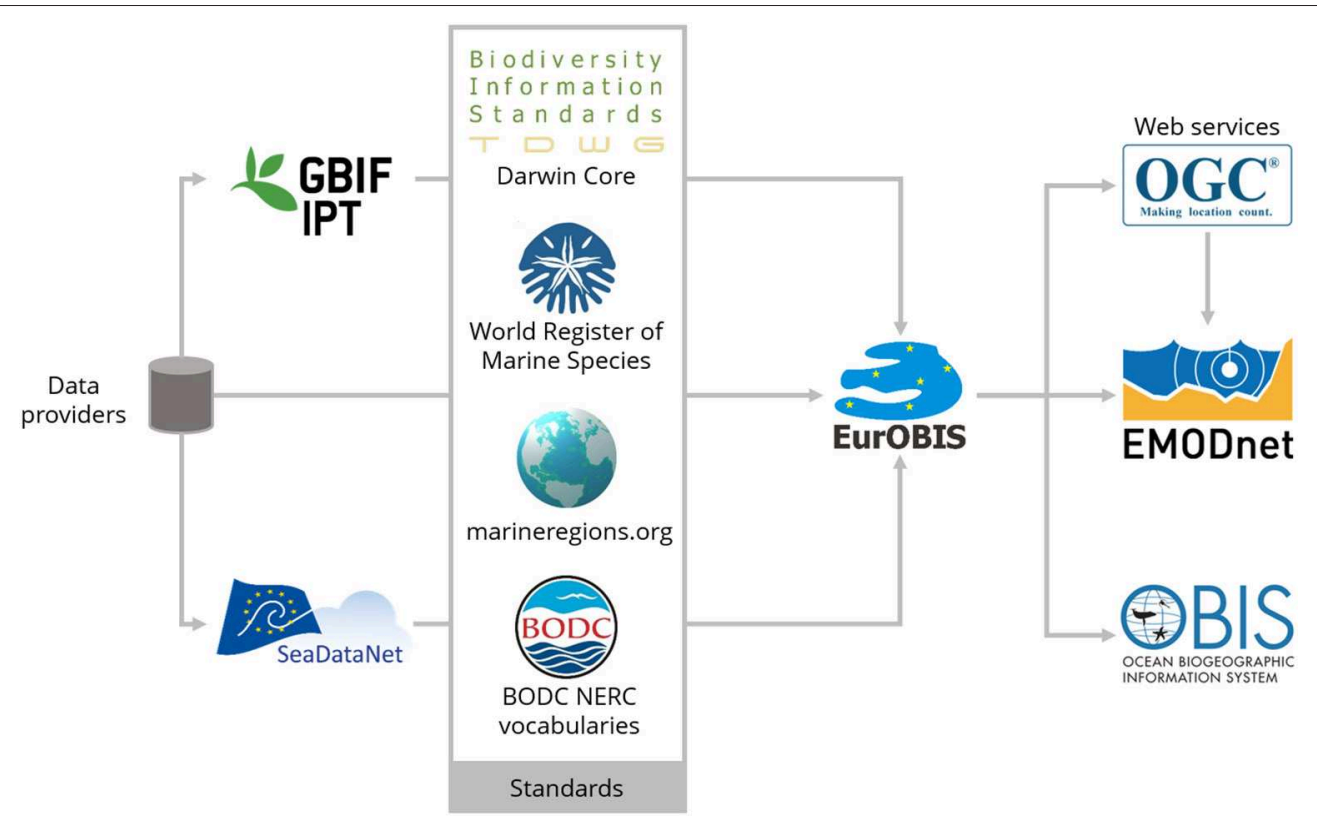

FIGURE 5 | Representation of data flow used within EMODnet Biology.

\section{Data Flow}

EMODnet biology uses the EurOBIS data system to harmonize and centralize biogeographic data on marine species collected by European institutions (Figure 5). The data that flows to EurOBIS is being mapped to the Darwin Core Terms. The purpose of these terms is to facilitate data sharing by providing a welldefined standard core vocabulary in a flexible framework to minimize the barriers to adoption to ensure interoperability and to maximize reusability.

EurOBIS receives its data through different pathways:

- Data providers can set up an Integrated Publishing Toolkit (IPT)-instance to serve their data in Darwin Core Archive Format (DwC)

- Individual providers can provide their data in Biological ODV format and serve through the SeaDataNet infrastructure, which is semi-automatically mapped with Darwin Core

- Individual providers can send their data to EurOBIS by email or as a service in different formats which are manually mapped to the Darwin Core

- In addition, the two European sub-nodes-OBIS Black Sea and MedOBIS-provide their data to EurOBIS, thus capturing all the marine European data in one system.

EurOBIS is in close communication with OBIS-SeaMap. OBIS-SeaMap-the Ocean Biogeographic Information System Spatial Ecological Analysis of Megavertebrate Populationsis a spatially referenced online database, aggregating marine mammal, seabird, and sea turtle observation data from across the globe. Datasets from OBIS-SeaMap containing European data are also made available to EMODnet users.

EurOBIS acts as the responsible node to make these data available to the OBIS community and in turn publishes the data through the OBIS database. Data that contribute to EurOBIS and OBIS are subject to a series of quality control steps, including for taxonomic nomenclature, and geographical location.

\section{Products}

EMODnet Biology produces digital data products allowing analysis of changes in species abundance and extent over time and space (Figure 6). This work was initiated with the development and production of gridded map layers from different data sources showing the average abundance of several species per functional species group for different time windows (seasonal, annual, or multi-annual) using geospatial modeling. These products are being expanded by: (1) integrating biological trait information to calculate spatial products for biological indicators (vulnerable vs. sensitive benthic communities, invasive species); (2) compiling historical data that can be used for reconstruction of long-term trends for some selected groups; and, (3) integrating environmental data layers that can be used as the basis for Species Distribution Models.

\section{Portal and Services}

The EMODnet Biology Portal ${ }^{23}$ allows public access to and viewing of data, metadata, and data products of marine species occurring in European marine waters. It offers different services including:

- Data Catalog-The data catalog is the easiest way to access nearly 1,000 datasets available through EMODnet Biology. The catalog contains information on the where, when, what, how, and who of the different datasets, using ISO19115-compliant metadata descriptions. Datasets can be filtered by multiple

\footnotetext{
${ }^{23}$ www.emodnet-biology.eu
} 

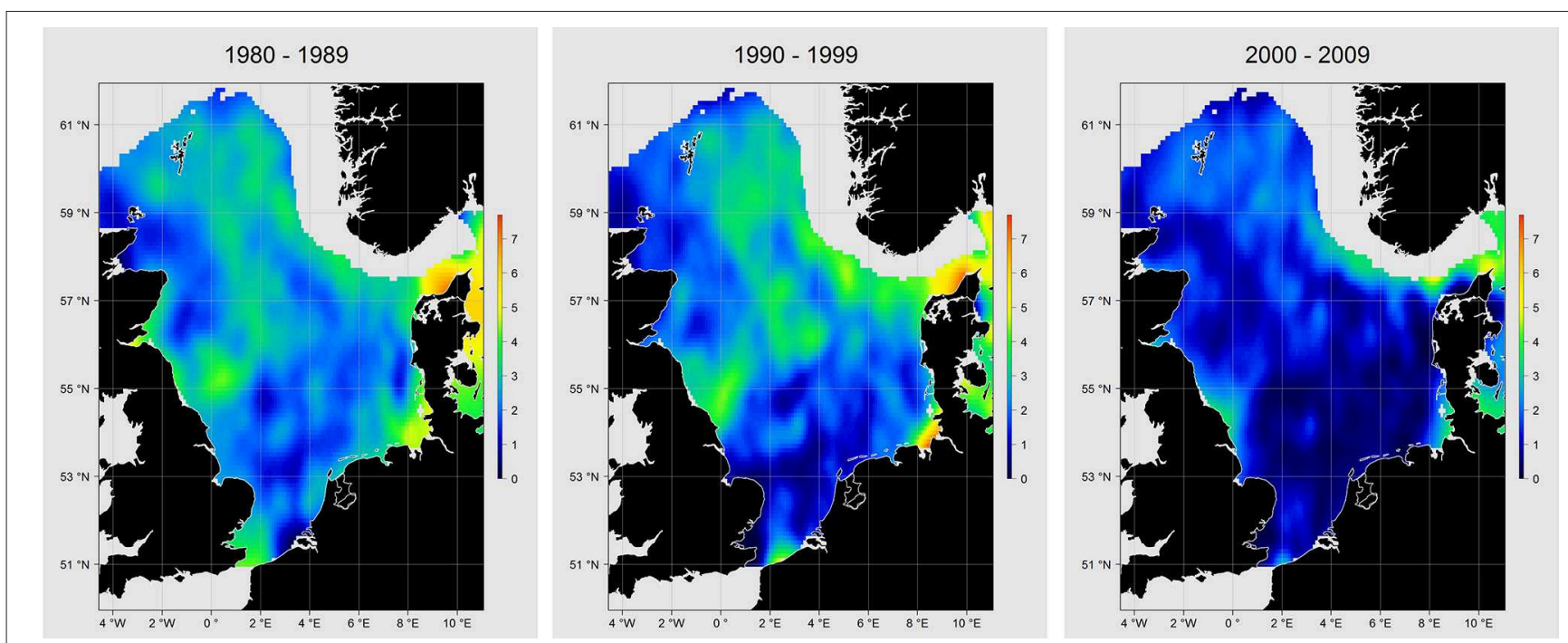

FIGURE 6 | Production of gridded map layers using geospatial modeling, showing the average abundance of Cod (Gadus morhua) in the North Sea showing stock depletion. Scale: log-transformed CPUE.

parameters via the advanced search from taxon, to institute, to geographic region. Each of the resulting datasets then links to a detailed fact sheet containing a link to original data provider, recommended citation, policy, and other relevant information. Most datasets have a CC-BY ${ }^{24}$ license.

- Data Download Toolbox-The data download toolbox allows the users to filter and select data through a step-wise approach, e.g., perform predefined geographic and temporal selections, add specific taxonomic or functional filters, select data with a certain quality and precision or that contain additional measurements beyond occurrences. A data file will be generated that can be downloaded as a csv-file or can be accessed via a WFS web service. The query itself can also be stored as a JSON-file.

- Map viewer-The data portal allows users to search for datasets by species list (e.g., benthos, fish, algae...) and by both scientific and common name. The selected taxon can be plotted in an integrated map viewer, which includes administrative and environmental layers that can be toggled on and visualized simultaneously.

- Atlas of Marine Life Data-In this section of the portal, products are structured around the EOVs for Biodiversity. Data products can be visualized and product stories have been created to display detailed information on the scientific rationale for each product, a link to the underlying datasets, a description of the methodology and a link to access the code and workflows.

- Web Services-All species occurrence data (species observations) are available as WFS as are additional measurements linked to the occurrence. The gridded abundance data products are available as WFS/WMS.

$\overline{{ }^{24} \text { https://creativecommons.org/licenses/ }}$

\section{THE OTHER EMODnet STRANDS}

\section{EMODnet's Sea-Basin Checkpoints}

User requirements are a priority for EMODnet, so a series of "Sea-basin Checkpoints" were established, starting with the Mediterranean and North Sea in 2013 and extending to the Arctic, Atlantic, Baltic Sea, and Black Sea in 2015. These aimed to assess whether the observation networks, surveying strategies, and data access met users' requirements in those six regional European sea-basins.

The concept of EMODnet Sea-basin Checkpoints was introduced within the Green Paper "Marine Knowledge 2020: from seabed mapping to ocean forecasting" (European Commission, 2012). In spite of EU initiatives such as EMODnet, CMEMS and the Data Collection Framework (DCF) for Fisheries, that aimed to deliver seamless layers of marine data across national boundaries, there are still shortcomings with the availability and accessibility of EU marine data. Furthermore, there was no overall view of the priorities for further data collection or assembly. The EMODnet Checkpoint initiative was the first of its kind to begin to link all existing monitoring data at the level of the sea-basins and assess them in order to provide advice for future improvements to Europe's observation capacity, as well as identifying significant bottlenecks restricting wider data availability.

For each of the sea-basins, the teams working in the Checkpoints acted as surrogate users attempting to address a number of challenges (see Table 5 for details about the expected outputs). The outputs of the challenges were then reviewed by panels of stakeholders and translated into reports that assessed the adequacy of the data, in terms of what is available and how fit-for-purpose it is, bearing in mind the particular challenge they were undertaking. Each of the six Sea-basin Checkpoints teams have approached these assessments using different methods, always striving to maintain the user perspective (see Pinardi et al., 
TABLE 5 | Description of the challenges that the checkpoints had to attempt with their corresponding expected outputs.

\begin{tabular}{|c|c|}
\hline Challenge & Description of outputs \\
\hline Wind farm siting & $\begin{array}{l}\text { Determine the suitability of sites for development of a wind farm. All aspects should be considered: wind strength, seafloor geology, } \\
\text { environmental impact, distance from grid, shipping lanes-even if one of the factors makes this a no-go scenario. }\end{array}$ \\
\hline Marine Protected Areas (MPA) & $\begin{array}{l}\text { Analyze the existing network of marine protected areas and: (i) categorize them according to the classification used by the } \\
\text { International Union for Conservation of Nature; (ii) determine whether the network constitutes a representative and coherent network } \\
\text { as described in article } 13 \text { in the Marine Strategy Framework Directive; (iii) determine how they are likely to be affected by climate } \\
\text { change. }\end{array}$ \\
\hline OilPlatform Leak & $\begin{array}{l}\text { The contractor will be informed that there is a leak from an oil platform at a time to be decided by DG MARE. The contractor will not } \\
\text { receive an advance warning of the exercise. The contractor will determine the likely trajectory of the slick and the statistical likelihood } \\
\text { that sensitive coastal habitats or species or tourist beaches will be affected. The contractor will indicate what information can be } \\
\text { provided within } 24 \text { and } 72 \mathrm{~h} \text {. }\end{array}$ \\
\hline Climate & $\begin{array}{l}\text { Determine: } \\
\text { - change in average temperature at surface, } 500 \mathrm{~m} \text { depth and bottom on a grid, over the past } 10 \text { and } 50 \text { years } \\
\text { - time series of average annual temperature at sea surface and bottom } \\
\text { - time-series of average annual internal energy of sea } \\
\text { - average extent of ice coverage over the past } 5 \text { years, past } 10 \text { years, past } 50 \text { years, past } 100 \text { years plotted on maps } \\
\text { - total ice cover in sea }(\mathrm{kg}) \text { over the past } 100 \text { years plotted as time series. }\end{array}$ \\
\hline Coasts & $\begin{array}{l}\text { Determine: } \\
\text { - In the coasts of all coastal states, the average annual sea-level rise per stretch of coast (absolute and relative to the land), and for } \\
\text { 10, } 50 \text {, and } 100 \text { years. This should be provided in tabular form and as a map layer; } \\
\text { - In the coasts of all coastal states, average annual sediment balance (mass gained or lost per stretch of coast) for } 10,50, \text { and } 100 \\
\text { years. This should be provided in tabular form and as a map layer. }\end{array}$ \\
\hline Fisheries management & $\begin{array}{l}\text { Produce tables for the whole sea-basin of: (1) mass and number of landings of fish by species and year; (2) mass and number of } \\
\text { discards and bycatch (of fish, mammals, reptiles, and seabirds) by species and year. }\end{array}$ \\
\hline Fisheries impact & $\begin{array}{l}\text { Produce data layers (gridded), showing the extent of fisheries impact on the sea floor, in particular estimate: (1) area where bottom } \\
\text { habitat has been disturbed by bottom trawling (number of disturbances per month); (2) change in level of disturbance over the past } \\
10 \text { years; (3) damage to sea floor to both living and non-living components. }\end{array}$ \\
\hline Eutrophication & $\begin{array}{l}\text { Produce data layers (gridded) showing: (1) seasonal averages of eutrophication in the basin for past } 10 \text { years; (2) change in } \\
\text { eutrophication over the past } 10 \text { years. }\end{array}$ \\
\hline River inputs & $\begin{array}{l}\text { For each river bordering the sea-basin, a time series of annual inputs to sea of: } \\
\text { - water (mass and average temperature) } \\
\text { - sediment } \\
\text { - total nitrogen } \\
\text { - phosphates } \\
\text { - salmon } \\
\text { - eels }\end{array}$ \\
\hline Bathymetry & $\begin{array}{l}\text { Sea-basin digital map of: } \\
\text { - water depth } \\
\text { - contour map of water depth for sea-basin in vector format in interval of } 100 \mathrm{~m} \text {, including coastline priority areas for surveying for } \\
\text { safer navigation taking into account emerging needs } \\
\text { - uncertainty in water depth for Black sea-basin }\end{array}$ \\
\hline Alien species & $\begin{array}{l}\text { Table and digital map of alien species in the sea-basin: species name } \\
\text { - family (fish, algae, mammals, sponges etc.) } \\
\text { - year of introduction } \\
\text { - season for introduction (climate change, ballast water discharge etc.) } \\
\text { - geographical area } \\
\text { - impact on ecosystem and economy }\end{array}$ \\
\hline
\end{tabular}

2017 for a description of the method used in the Mediterranean). This user-oriented view makes this exercise unique and original, facilitating the development of more tangible recommendations for the future development of Europe's ocean observing framework and its evaluation. Pearlman et al. (2019, this issue) considers the checkpoints as "the first community-based best practice for monitoring systems that incorporates end-user products." Also in this issue (Buck et al., 2019), highlights the checkpoints as an example of data democratization, where there "the user defines the way the information derived from data is converted to knowledge."
The products listed in the challenged areas could not always be generated (in requested quantity and quality) due to different reasons:

- Data do not exist: this was generally related either to gaps in coverage (certain areas were not sampled) or insufficient resolution (the sampling density was not enough for the application pursued).

- Data exist but are not available: this can happen when the data cannot be found easily, or even if they are found there are restrictions of access. This can hinder fulfilling the challenges in a reasonable time or under a certain cost. 
- Data exists but are not appropriate for the use: this can encompass many characteristics like timeliness, accuracy, precision, completeness, update frequency of the series or the type of format (more or less standard).

A summary of the main findings and suggestions is presented in Appendix A1. More information about the outputs of the challenges and the results of the assessments is available through a number of websites that can be accessed through the EMODnet Central Portal ${ }^{25}$.

All Checkpoints have put in place management systems that identify which datasets have been used for each challenge and how those datasets have been assessed and used to create the products. This allows for repeatability and traceability of the assessment results. This monitoring assessment framework could be used periodically (a 3-5 year cycle was suggested) and turn into a "Checkpoint service," with the inclusion of new challenges and the development of new products depending on needs (blue growth, climate, environmental policies).

\section{Data Ingestion}

Over the past years, EMODnet has made huge advances in facilitating access to data from many sources. However, data still remain hidden or unusable because data holders lack the resources to share their data, due to restrictions in terms of resources, available time or technical know-how. EMODnet's Data Ingestion facility tackles these problems, by reaching out to data holders and offering a support service to assist them in releasing their data for subsequent processing and quality control and ultimately publishing as open data.

Key targets of the data ingestion service are organizations from public, research, and private sectors who are managing marine datasets for bathymetry, geology, physics, chemistry, biology, seabed habitats, and/or human activities and who are not yet connected and contributing to the existing marine data management infrastructures. The service aims to motivate and support those potential data providers to release their datasets for safekeeping and subsequent free distribution through EMODnet. The Ingestion portal provides services for submission, publishing, and guidance. The life-cycle of a data submission is divided into two phases:

- Phase I: from data submission to publishing "as is";

- Phase II: further elaboration and integration (of subsets) in national, European, and EMODnet thematic portals.

The EMODnet network for validating and processing data submissions is recruited from the EMODnet Ingestion and EMODnet thematic portal consortia and at present comprises circa 50 qualified data centers for marine chemistry, physics, geology, bathymetry, biology, seabed habitats, and human activities data. Active marketing and promotion toward potential data providers with banners and animation is ensured through the EMODnet Central Portal and thematic portals, as well as during conferences and workshops. On top of that there is national marketing undertaken by the EMODnet Ingestion

$\overline{{ }^{25} \mathrm{http}: / / \mathrm{emodnet} \cdot \mathrm{eu} / \text { checkpoints }}$ ambassadors. This includes reaching out to their local networks of contacts, organizing national EMODnet days to build relationships, and distributing promotional media.

\section{Central Portal}

The EMODnet Central Portal was implemented to centralize information about EMODnet. It is a single-entry point to data, metadata, and data products made available by the 7 EMODnet thematic portals as well as a gateway to the other EMODnet strands (Checkpoints and Data Ingestion). The EMODnet Central Portal also offers its own user-oriented data services comprising a geoviewer, a metadata catalog, a query tool and documentation on how to access data and data products using web services. The geoviewer provides access to over 40 different data products, in combination with additional data layers and administrative units, all of them based in OGC web services. Together with the metadata catalog, these services allow a wide range of professional users and general public to explore and visualize what EMODnet has to offer, with direct links to the original data and data products on the thematic portal webpages. The ongoing documentation on web services and data access is intended for data scientists or scientists with a strong data analysis background, as well as programmers, to help them understand how to access and analyze the data, create workflows or build applications using EMODnet data and web services. Finally, the query tool is aimed at marine spatial planners and/or practitioners, who would like to retrieve processed information from multiple thematic data products via one single interface in order to get a summary overview of a marine area under assessment. The EMODnet Central Portal works in close cooperation with the thematic lots and the EMODnet Secretariat to implement best practices which improve inter-operability of the data services and improve the user experience and uptake.

EMODnet Central Portal has become a powerful tool to communicate and disseminate information about EMODnet. The Central Portal website has regularly updated sections such as "News Flash," "Events," and "Use Cases" sections, which give visibility to EMODnet achievements and demonstrate their impact (Figure 7).

\section{EMODnet AS A USER-ORIENTED SERVICE}

EMODnet has transformed over the years from a bottom-up initiative developed largely from data provider communities to a more user-oriented service. The uptake and use of EMODnet data products and services by a wide range of users lie at the heart of assessing the success of the programme, and is central to the current range of activities. Through the (1) identification of the stakeholders and use cases and (2) the engagement with key stakeholders, EMODnet can work toward products and services that can be truly considered "essential."

EMODnet thematic groups report quarterly on a set of progress indicators that include, amongst others, number of visitors including their sector of provenance (distributed into four categories: Academia/Research; Government/Public 


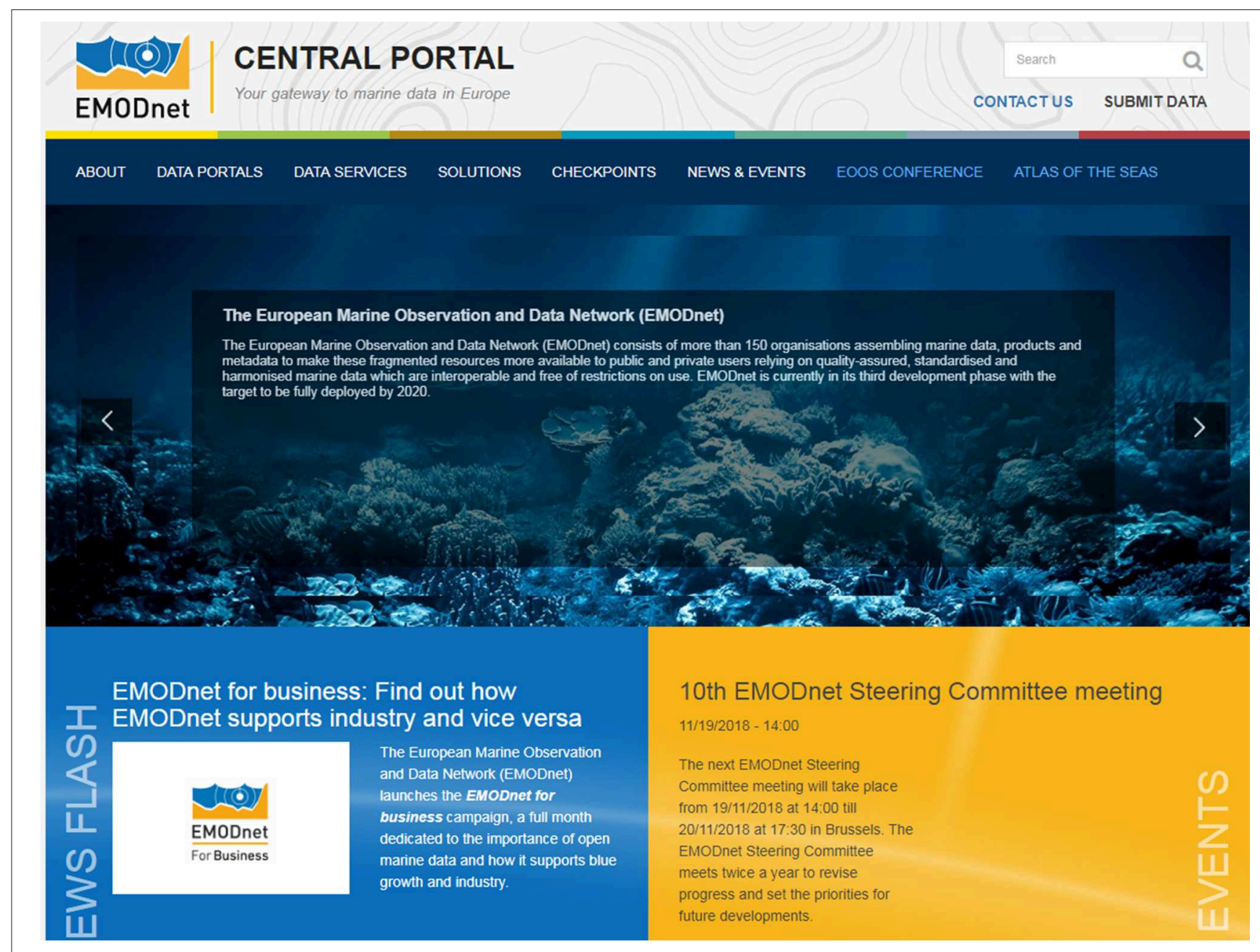

FIGURE 7 | Entry page of EMODnet Central Portal website providing a unified access to all EMODnet resources.

Administration; Businesses \& Private; NGOs/Civil Society), as well as the main applications for the data/data products downloaded. From these indicators it is clear that academia and researchers constitute the main share of EMODnet visitors for all the thematic portals alike. However, the difference between this category and the others can be vary considerably. For instance, according to the report of the last quarter of 2018, $90 \%$ of Biology portal users identified themselves as belonging to research/academia while the other three main sectors were negligible. However, up to $25 \%$ of Geology and $30 \%$ of Human Activities users belonged to the private sector, whereas $30 \%$ of Chemistry users identified themselves as coming from an NGO or the Civil Society. In the same report, the percentage of users belonging to Government/Public Administration ranged between 5 and 15\% (except for Chemistry, where the share was $21 \%)$.

Reported applications reflect the multidisciplinary nature of the EMODnet portfolio and reveal its high potential. Not surprisingly, many of the uses are research related, e.g., development of, validation of or comparison with other data or models of all kinds (species distribution modeling, wave modeling, tsunami modeling...); input data and/or support for presentations in the framework of lectures, MSc theses, and $\mathrm{PhD}$ dissertations. Other uses are related to the private sector, e.g., in the framework of prospection projects such as wind farming, cable routing or dredging. Studies supporting Marine Spatial Planning or Marine Protected Areas management (Government/Public Administration) are also mentioned.

In addition to that, EMODnet Secretariat collects and documents use cases that show how the EMODnet service has been used by industry, public authorities, researchers and civil society. These use cases are published regularly on the Central Portal webpage ${ }^{26}$ classified by EMODnet theme and sector.

Whilst the requirements for what is considered an "essential" data product vary from region to region and at different geographic scales, the process for stakeholder engagement remains the same. It is critical that the development of data products is end-user driven, answering specific questions or

\footnotetext{
${ }^{26}$ http://www.emodnet.eu/use-cases
} 
addressing existing gaps in knowledge. EMODnet groups have engaged with users since the beginning through different means. Surveys and questionnaires are regularly used to collect information from users, especially when planning portal updates, both in terms of content, type of products offered, and design. The feedback received has helped the EMODnet portals to progressively implement new tools that allow for a better user experience when accessing data, metadata, and products.

Engagement with individual users of the portals is also done via the Helpdesk service that is available in each of the EMODnet thematic portals. With this service, visitors to the portals can receive fast support in their searches and general navigation through the portals.

Workshops are also valuable tools to ensure that stakeholders views are captured, and that those stakeholders can suggest further product developments. For example, in 2017 the EMODnet Biology group trialed an approach to ensure the wide range of stakeholder views and requirements was captured, whilst ensuring that the global context was inherent within the process. An international workshop drew on the expertise of a wide range of practitioners actively involved in the coordination and management of marine biodiversity. Representatives from four European regional seas were present, participants from transatlantic and global partnerships, industry, conservation, and management bodies to discuss the development of a core set of data products to be delivered through EMODnet Biology. Participants were invited to identify existing gaps in data products and to highlight the types of data and information they required. The range of responses across stakeholders clearly indicated that the development of generic, or single-use data products were unlikely to meet the complex requirements of the varied stakeholders.

Not only are those who use EMODnet resources important stakeholders. Engaging with data providers is obviously also fundamental. As mentioned in the introduction, visibility of data ownership is one of the core principles of EMODnet so that the work of institutions collecting and processing data can be properly acknowledged. Specific examples of this engagement can be found via tracking tool like the ones offered by EMODnet Physics. Data providers receive reports by email informing them about the use (number of hits, most viewed datasets etc.) of their platforms/datasets on the EMODnet Physics portal.

In other cases, most of its efforts are concentrated in meeting the needs of one specific group of customers. This is the case of EMODnet Chemistry, for whom public European institutions, and even more those related to MSFD implementation are their preferential target user. To achieve this challenging goal, a tight connection with EEA, Regional Sea Conventions (OSPAR, HELCOM, Black Sea Commission, and MED POL), JRC and ICES has been established, and regular meetings are held. Online workshops with groups of MSFD experts have been carried out to identify needs focused on eutrophication, contaminants, and litter.

Participation in external events and business conventions as well as organizing specific user-oriented activities such as the
EMODnet hackathon series called Open Sea $\mathrm{Lab}^{27}$ are another way of collecting relevant information from users to understand what is working well, what gaps exist, and what barriers remain for users to fully exploit the available resources. Another way to engage more organizations is by broadening the Network itself. For this reason, the Secretariat created the EMODnet Associated Partnership scheme in 2017 for interested organizations to join without heavy administrative or contractual arrangements to allow EMODnet to grow as an inclusive network.

In 2018, EMODnet also contributed to developing inclusive and open stakeholder engagement across the European ocean observing and data management communities. This culminated in the first EOOS Conference (Larkin et al., 2019), specifically aimed to connect diverse and disparate communities across Europe. Funded by the European Commission and co-organized by EMODnet, the European Marine Board and EuroGOOS, the Conference brought together about 300 stakeholders from the ocean observing, monitoring, and data management communities and users, spanning public and private sectors and from research to monitoring for public authorities and for the blue economy.

\section{EMODnet IN THE NEXT DECADE}

In its third development phase (2017-2020), EMODnet is now sufficiently mature to provide considerable value for industry and the public sector. Despite this, there remains an opportunity for EMODnet to further mobilize new users to fully exploit this immense resource. Two areas in particular provide scope for further improvement: users beyond Europe and business users. Additional opportunities lie in aligning and, where possible, integrating with other European data and information sharing initiatives. EMODnet is already actively engaged in developing synergies with the European Atlas of the Seas (EAS), frameworks such as the European Ocean Observing System (EOOS) and global initiatives such as the GEOSS geoportal, Together these activities and developments are expected to take EMODnet to a new dimension as one of the leading global actors in ocean observing, data management and information provision services for an expanding user base comprising the general public, professionals and data experts alike.

The EMODnet Secretariat's vision is to support the network by fostering a culture based on learning by doing, to listen to users and build on the strengths of each of the partners involved. Providing easy access to high quality, interoperable marine data, and products free of restrictions on use is clearly at the core of EMODnet. Nevertheless, EMODnet is more than a distributed data infrastructure. EMODnet provides a collaborative platform for them to advance work on standards, to develop synergies, reduce fragmentation, and create a cohesive community capable of solving problems that no single entity can address on their own. In the European context, EMODnet illustrates that by working together we can achieve results which would never be possible if countries were to act on their own.

\footnotetext{
${ }^{27}$ www.opensealab.eu
} 


\section{The Main Axis of the Strategic Vision for the Next Few Years}

The key short-term objective for EMODnet partners is to deliver the vision target of a seamless multi-resolution digital seabed map of European waters by 2020, covering all EMODnet themes, easily accessible, interoperable, and free of restrictions on use. This objective will be accompanied by a process that helps European countries maximize the potential of their marine observation programmes via data adequacy assessment at seabasin scale. As already suggested, the Checkpoint exercises could be undertaken periodically as part of this process.

The main challenges that will need to addressed by the EMODnet data portals in the third and final development phase (2017-2020) are to (1) further improve data coverage, quality, and resolution (more data, new parameters, new products, etc.); (2) improve coherence, harmonization and interoperability, within each thematic area, amongst the different EMODnet thematic data portals and with international initiatives/systems; (3) improve existing and develop new integrated central access data services to search, visualize and retrieve data resources from different thematic sub-portals simultaneously; (4) improve accessibility of the available data, products, and services via remote machine-to-machine connections and provide adequate documentation; (5) further improve the visibility of the resources, in particular by intermediate users from the public and private sector to create value and by global users to support international ocean governance processes, amongst others; (6) demonstrate successes; and (7) strengthen the user/service-orientation.

\section{EMODnet for Global Users}

Whilst the focus of development within EMODnet and its thematic groups has been to support activities and the development of products at the European scale, this activity cannot take place in isolation. More than half of the 17 United Nations Sustainable Development Goals are related to the marine environment and the challenges of global data interoperability lie at the heart of ensuring a comprehensive evidence base is assembled to help achieve these goals. In addition, by 2030 the ocean economy is predicted to have a value in excess of three trillion US dollars (OECD, 2016). The need to balance the negative impacts on biodiversity and ecosystem services with sustainable growth and increasing demands has never been greater.

Without the development of inclusive, open standards and practices the capability to respond to these challenges is greatly diminished. Development must include the parallel provision of training, tools and services to lower the barriers to data uptake for a truly global audience to participate. Global networks are able to reach a wide community and ensure promotion and access to standards. However, without regional integration the ability to deliver meaningful, informative, and high-utility products is greatly reduced. Most EMODnet thematic assembly groups are providing these products and services at the European level while actively working with the global community to ensure the highest degree of integration and interoperability.
Since 2016, DG MARE has been developing an EMODnet internationalization strategy with the objective to make EMODnet more visible and relevant for international users/stakeholders and to strengthen interoperability with global data systems and initiatives. This is done among others via the creation of EMODnet dedicated community sections on the central portal, by feeding data products to global repositories (e.g., Ocean Data Portal and GEOSS geoportal), and by ingesting/providing data from areas beyond European waters. As part of these efforts, EMODnet partners will continue to connect and participate in projects with an international scope (e.g., EU funded projects such as ATLAS ${ }^{28}$, AtlantOS ${ }^{29}$, ODIP ${ }^{30}$, and EuroGEOSS $\left.{ }^{31}, \ldots\right)$, contribute to setting standards at European and international level, and establish and share best practices (e.g., via the IOC-UNESCO ocean best practices repository).

\section{Future User Orientation and Stakeholder Engagement}

The transition to more user-oriented developments underpinned by stakeholder engagement is a priority for EMODnet to become a fully user-driven service. This will require much greater interaction with users and stakeholders. To achieve this, the EMODnet portals will move beyond data provision, to become also a facility for engagement and communication with both data providers and users. Dedicated services such as community portals for specific projects or initiatives, in return for data or other contributions already exist (e.g., EMODnet Physics for AtlantOS, JERICO-NEXT, SOOSmap, and others) and should be further explored. Providing a dashboard function with statistics on usage and information to data providers is another way to strengthen links with core stakeholders and secure the integrity in the long term (already available for EMODnet Physics). In order to better understand user needs, EMODnet will continue to actively seek feedback and collect information about usage via online surveys, helpdesk functions, feedback forms, download forms, and targeted user assessments.

Specific emphasis will continue to be placed on making EMODnet more known and used by businesses, both as provider and user. In particular, SME's, consultancies and intermediate users will be a key target, as they can be considered to be the catalyzers of value creation along the marine knowledge value chain.

\section{Strengthen Connectivity Between Different Components of the Marine Knowledge Value Chain}

The marine knowledge value chain can be considered to cover the progression of data from their collection to their use, with value being created at various stages, from the acquisition of metadata

\footnotetext{
${ }^{28}$ https://www.eu-atlas.org/

${ }^{29}$ The idea for EMODnet Atlantic pages originated from work done in the framework of the AtlantOS project on how marine data portals can better support and engage with stakeholders relying on ocean observing and data across the Atlantic http://www.emodnet.eu/atlantic-1

${ }^{30}$ http://www.odip.eu/

${ }^{31}$ https://www.earthobservations.org/activity.php?id=145
} 
on collection, to processing the data into information products that can ultimately be used for decision making or economic value creation. Up until 2017, EMODnet had focused mainly on data assembly, harmonization, and sharing. To fully realize the potential of the now mature and operational EMODnet, there is a need to expand the focus and scope of activities along the entire marine knowledge value chain, from merely data sharing toward (1) more upstream (data collection) by improving the data ingestion process and aligning with the emerging EOOS; and (2) more downstream by making EMODnet data products and information outputs more relevant and accessible to a wider public, via sharing tools such as the European Atlas of the Seas (EAS), which, since 2017, is being further developed by the EMODnet Secretariat. The strengthening of these interlinkages will hopefully contribute to a structuring process leading to a coherent EOOS, well-aligned with EMODnet and value-added information service providers, with the scale and visibility to create an ocean business market/ecosystem around data collection, management/sharing and the generation of information services for end-users.

In addition, with the upcoming United Nations Decade on Ocean Science for Sustainable Development and the wider UN 2030 agenda and Sustainable Development Goals (SDGs) EMODnet will accelerate its efforts to make its services providing data and data products more interoperable with wider European, regional, and International data initiatives. This will include applying, where relevant, ocean best practices such as semantic ontology to ensure data and data products are also more discoverable to a wider user community and searchable according to their relevance to SDGs.

\section{Sustainability of EMODnet}

EMODnet does not operate in situ observing platforms but assembles observations in cooperation and coordination with existing programmes and projects (the data initiatives, mentioned in Table 2). As already explained, these data initiatives are supported and maintained with major input from national stakeholders. These stakeholders are research and governmental organizations that are involved in marine data collection and data management, running data centers (data originators and data assembly centers). This implies that the upstream pillars of EMODnet are well-funded, supported by long-term initiatives and operations within national strategies related to the marine environment. By building upon these existing initiatives and developing beneficial partnerships, EMODnet has ensured an optimization of resources.

On the downstream part, EMODnet has made huge progress, not only in unlocking and facilitating access to data, but also in developing added-value services and products for varied user communities. There are many examples that show EMODnet impact like, for instance, the EMODnet Bathymetry digital terrain model (DTM) of the European seas. This DTM (resolution of $1 / 16^{*} 1 / 16$ arc min, i.e., grid of $115 \mathrm{~m}$ resolution) is the best on the market and finds its way to many numerical modelers for tide and wave forecasting, offshore industry such as oil and gas companies, wind farm operators, dredging companies, pipeline engineering companies, coastal protection managers, and many others. Another good example is EMODnet Chemistry that brings together a large number of chemical data on eutrophication and contaminants that serve the MSFD process. This has led to the decision by EEA to accept EMODnet as an important source of data for supporting the MSFD process and advising Member States to make use of EMODnet for reporting as one of the preferred options. Likewise, the recent Horizon 2020 Work Programme H2020-2018-2020 for "Food security, sustainable agriculture and forestry, marine, maritime and inland water research and the bioeconomy" reads that "Data collected shall be in line with agreed standards, be openly available via portals (including EMODnet)." DG MARE is also building agreements for cooperation with other European initiatives such as Copernicus, the DCF the MSP Directive, and the MSFD, for greater synergy and integration with a clear goal toward long-term integration. In summary, EMODnet's crucial role in continuing to support and contribute to these important policy objectives, as well as to Europe's blue economy, guarantees its sustainability into the future.

While the political commitment clearly exists to maintain EMODnet as a long-term permanent service, the exact scope, governance, and mechanism of funding beyond 2020 have yet to be fully defined. The Marine Knowledge 2020 Strategy mapped out the evolution of EMODnet until 2020. Now is the time to plan for the post 2020 EMODnet era. In November 2019, all EMODnet partner organizations and stakeholders will gather to consider the future roadmap of EMODnet on the longer term. It is expected that the aforementioned priorities of the final development phase (leading up to 2020) will also drive how EMODnet evolves beyond 2020.

\section{CONCLUSIONS}

EMODnet originated from the need to unlock the potential of fragmented and hidden marine observations and data stored in a myriad of data systems and repositories scattered all over Europe. This was critical because the data collected through observations can only generate knowledge and innovation if Europe's engineers and scientists are able to find, access, assemble and apply them, efficiently and rapidly. Since its creation in 2009, EMODnet has greatly alleviated this problem by providing access to a broad range of harmonized marine observations/data and data products across seven thematic domains.

User feedback indicates that there is a general sense of appreciation for the work done by the thematic assembly groups, in particular to collate and harmonize the often disperse and fragmented data resources. With a growing range of data services and steady improvements of data products of broad interest, EMODnet shows what can be achieved if we work together beyond national borders. It is a true success story of European collaboration.

However, EMODnet has done much more than providing access to data, metadata, and products. It has created a network and community of experts and specialists working to promote the development and adoption of standards, sharing 
best practices, and technical solutions to promote integration and interoperability between various systems. Through a series of data stress-tests, the EMODnet Checkpoints have helped with the identification of important data gaps or issues in data collection or sharing that, if left unchecked, inhibit our ability to address important societal questions. But perhaps its greatest added value is that EMODnet acts as a platform for collaboration, bringing together key European ocean observation/data providers, integrators, networks, and infrastructures (EuroGOOS ROOS, CMEMS, SeaDataNet, OBIS, ICES, PANGAEA, Regional Sea Conventions, hydrographic offices, geological surveys, etc.). As such it has greatly contributed to reducing fragmentation and increasing efficiency in the European marine data landscape, as well as in instigating a coordinated, interoperable data sharing framework. EMODnet has also been instrumental in nourishing and advancing the developing culture of open data sharing, in the public sector, academia and the maritime industry, both in Europe and beyond.

In order for data providers and users to invest time in both using and contributing to any data provision service, they have to trust in the reliability of the service. As a long-term EU data initiative supported by the European Commission, EMODnet has gained this trust amongst many providers and users. To build on this, EMODnet is continuously evolving, improving the tools available and widening thematic and geographic coverage. It is uniquely multidisciplinary, pan-European and increasingly global in scope and coverage, largely as a result of the internationalization strategy. Making EMODnet services, data and products more relevant and available to international users and data sharing facilities (e.g., GEOSS geoportal) will therefore become even more important in the future than it has been until now.

With the promotion efforts of the EMODnet Secretariat and the creation of a central access portal, the number of satisfied users has steadily grown over the years. As such, EMODnet has greatly increased the visibility, potential and re-use of Europe's wealth of marine observations, and data resources.

While EMODnet will maintain its core function of providing access to marine data, metadata, products, and services, it will also continue to grow and further strengthen engagement with stakeholders, users, and other initiatives, to create new off-shoots

\section{REFERENCES}

Buck, J. J. H., Bainbridge, S. J., Burger, E. F., Kraberg, A. C., Casari, M., Casey, K. S., et al. (2019). Ocean data product integration through innovation-the next level of data interoperability. Front. Mar. Sci. 6:32. doi: 10.3389/fmars.2019.00032

Busalacchi, A. J. (2009). "Celebrating a decade of progress and preparing for the future: ocean information for research and applications," in Proceedings of OceanObs'09: Sustained Ocean Observations and Information for Society, Vol. 2, eds J. Hall, D. E. Harrison, and D. Stammer (Venice :ESA Publication WPP-306).

Calewaert, J. B., Weaver, P., Gunn, V., Gorringe, P., and Novellino, A. (2016). "The European Marine Data and Observation Network (EMODnet): your gateway to european marine and coastal data," in: Quantitative Monitoring of the Underwater Environment. Ocean Engineering \& Oceanography, Vol 6, eds all along the marine knowledge value chain, at European and global level.

\section{AUTHOR CONTRIBUTIONS}

$\mathrm{BM}$ is the lead author, coordinated the drafting and wrote the part describing EMODnet Checkpoints. AN, MV, and SC are the lead authors of the in-depth sections describing Physics, Chemistry, and Biology portal, respectively. AG, NA, TS, and AP are coordinators of the rest of EMODnet portals. QH, NP, BK, JP, JS, and AVP are coordinators of the EMODnet Checkpoints. $\mathrm{SI}$ is the coordinator of the Data Ingestion project together with DS, who wrote the corresponding text and provided input to Chemistry section as well as during the review process. J-BC wrote the forward-looking final part and conclusions. OM and PO wrote parts providing the background and describing the Central Portal, respectively. Other co-authors writing text were DL, GM, PG, and KL. AP, OM, NA, and NH also revised the text. SS assisted with the editing and formatting. The rest of the co-authors work actively in different strands of EMODnet and provided other types of inputs such as Figures and Tables or further comments.

\section{FUNDING}

Financial contribution from the European Union for EMODnet Secretariat coordination and technical development and maintenance of the EMODnet services via Regulation EU No 508/2014 of the European Parliament and of the Council of 15 May 2014 on the European Maritime and Fisheries Fund.

\section{ACKNOWLEDGMENTS}

EMODnet is a truly network driven pan-European collaborative initiative. As with all EMODnet developments and achievements, this paper would not have been possible without the efforts and contributions of the entire EMODnet community. We would also like to gratefully acknowledge the last-minute assistance of Sarina Versteeg in the first submission and the generous support and assistance of Nathalie Tonné during the review process.
B. Zerr, L. Jaulin, V. Creuze, N. Debese, I. Quidu, B. Clement, A. Billon-Coat (Cham: Springer), 31-46.

EEA Report No 2/2015 (2015). State of Europe's Seas. Available online at: http:// www.eea.europa.eu/media/publications/state-of-europes-seas

European Commission (2010). Marine Knowledge 2020 Marine Data and Observation for Smart and Sustainable Growth. Commission Communication COM(2010) 461, Publications Office of the European Union.

European Commission (2012). Marine Knowledge 2020 from Seabed Mapping to Ocean Forecasting. Green Paper, Publications Office of the European Union, Luxembourg. Available online at: https://ec.europa.eu/maritimeaffairs/sites/maritimeaffairs/files/docs/ body/marine-knowledge-2020-green-paper_en.pdf

European Union (2007). Directive 2007/2/EC of the European Parliament and of the Council of 14 March 2007 Establishing an Infrastructure for 
Spatial Information in the European Community (INSPIRE). Available online at: http://data.europa.eu/eli/dir/2007/2/oj

European Union (2008). Directive 2008/56/EC of the European Parliament and of the Council of 17 June 2008 Establishing a Framework for Community Action in the Field of Marine Environmental Policy (Marine Strategy Framework Directive). Available online at: https://eur-lex.europa.eu/eli/dir/2008/56/oj

Fischer, A. S., Hall, J., Harrison, D. E., Stammer, D., and Benveniste, J. (2010). "Conference summary-ocean information for society: sustaining the benefits, realizing the potential," in Proceedings of OceanObs'09: Sustained Ocean Observations and Information for Society, Vol. 1, eds J. Hall, D. E. Harrison, and D. Stammer (Venice: ESA Publication WPP306). doi: 10.5270/OceanObs09.Summary

Larkin, K., Marsan, A.-A., Tonné, N., and Calewaert, J.-B. (eds) (2019). EOOS Conference 2018 Report and Call to Action. Connecting European Ocean Observing Communities for End-to-End Solutions. Brussels: The Egg, 21-23.

OECD (2016). The Ocean Economy in 2030. Paris: OECD Publishing. Available online at: http://dx.doi.org/10.1787/9789264251724-en

Pearlman, J., Bushnell, M., Coppola, L., Karstensen, J., Buttigieg, P. L., Pearlman, F., et al. (2019). Evolving and sustaining ocean best practices and standards for the next decade. Front. Mar. Sci. 6:277. doi: 10.3389/fmars.20 19.0027

Pinardi, N., Manzella, G., Simoncelli, S., Clementi, E., Moussat, E., Quimbert, E., et al. (2017). "Stress testing the EU monitoring capacity for the Blue economy. Operational oceanography serving sustainable marine development," in Proceedings of the Eight EuroGOOS International Conference, eds E. Buch, V. Fernández, D. Eparkhina, P. Gorringe and G. Nolan (Brussels, Bergen EuroGOOS) 3-5

Roarty, H., Cook, T., Hazard, L., Harlan, J., Cosoli, S., Wyatt, L., et al. (2019). The global high frequency radar network. Front. Mar. Sci. doi: 10.3389/fmars.2019.00164

Rubio, A., Mader, J., Corgnati, L., Mantovani, C., Griffa, A., Novellino, A., et al. (2017). HF radar activity in european coastal seas: next steps toward a pan-European HF radar network. Front. Mar. Sci. 4:8. doi: 10.3389/fmars. 2017.00008

Shepherd, I. (2018). European efforts to make marine data more accessible. Ethics Sci. Environ. Polit. 18, 75-81. doi: 10.3354/esep00181

Troupin, C., Barth, A., Sirjacobs, D., Ouberdous, M., Brankart, J.-M., Brasseur, P., et al. (2012). Generation of analysis and consistent error fields using the Data Interpolating Variational Analysis (DIVA). Ocean Model. 52-53, 90-101. doi: 10.1016/j.ocemod.2012.05.002

Wilkinson, M. D., Dumontier, M., Aalbersberg, I. J. J., Appleton, G., Axton, M., Baak, A., et al. (2016). The FAIR guiding principles for scientific data management and stewardship. Sci. Data 3:160018. doi: 10.1038/sdata.2016.18

Conflict of Interest Statement: J-BC, OM, and KL were employed by company Seascape Belgium. AN and GM were employed by ETT Solutions Ltd. AP was employed by Cogea s.r.l. DS was employed by Maris BV. QH was employed by HR Wallingford. BK was employed by Arcadis N.V. PH was employed by Deltares.

The remaining authors declare that the research was conducted in the absence of any commercial or financial relationships that could be construed as a potential conflict of interest.

Copyright (c) 2019 Martín Míguez, Novellino, Vinci, Claus, Calewaert, Vallius, Schmitt, Pititto, Giorgetti, Askew, Iona, Schaap, Pinardi, Harpham, Kater, Populus, She, Palazov, McMeel, Oset, Lear, Manzella, Gorringe, Simoncelli, Larkin, Holdsworth, Arvanitidis, Molina Jack, Chaves Montero, Herman and Hernandez. This is an open-access article distributed under the terms of the Creative Commons Attribution License (CC BY). The use, distribution or reproduction in other forums is permitted, provided the original author(s) and the copyright owner(s) are credited and that the original publication in this journal is cited, in accordance with accepted academic practice. No use, distribution or reproduction is permitted which does not comply with these terms. 


\section{APPENDIX}

Appendix A1 | Main identified gaps and suggested solutions by the Checkpoints, disclosed by parameter.

Parameter GAP Suggestion

AIR
Wind
$\begin{array}{ll}\text { - Wind profiles observations above } 10 \mathrm{~m} \text { height } \\ \text { (required for Wind farm siting challenge) are scarce } \\ \text { and generally not public. } \\ \text { - Wind data for applications at the coast do not have } \\ \text { enough resolution (this is also the case for currents } \\ \text { and waves). }\end{array}$

\section{SEAWATER-PHYSICS}

Ocean currents

Waves

Sea level

Sea ice

\section{SEAWATER - CHEMISTRY}

Nutrients (nitrogen,

phosphates)

Chlorophyll-a

Dissolved oxygen

\section{SEAWATER-BIOLOGY}

Phytoplankton

Reptiles, Sea mammal, Birds counts, Birds migration routes

Alien species

\section{MATRIX FRESH WATER}

Water discharge
- Horizontal resolution of publicly available current data (models) is not enough for Wind farm siting and Oil spill challenges. More observational data would be desirable. Horizontal coverage is also an issue for the Atlantic Checkpoint.

- Public wave data (models) do not have enough horizontal resolution for Wind farm siting and Oil spill. Wave data are also important to study sediment transport at the coast. Again, resolution is too coarse for this kind of studies.

- The number of sea level stations providing long-enough time is insufficient and there should be more GPS-colocated tide gauges to fulfill the Coasts challenge (all but Baltic).

- Sea ice coverage is less of an issue than sea ice thickness, in particular for the Climate challenge (for Wind farm siting purposes it seems enough, because there are recent data).

- The coverage and resolution are not enough (except in the Baltic Sea), in particular at the coastal zone, and this hinders achieving the challenge in eutrophication.

- Same as above

- Same as above
Suggestion

- LiDAR could be an alternative for cost-effective monitoring, but it needs in situ wind profiles for calibration.

- High Frequency Radars (HFR) can become a key tool for monitoring currents, waves, and winds near the coast.

- Some Checkpoints used commercial solutions that provided fit-for-use data that enabled them to fulfill Wind farm siting challenge.

- As for wind data, HFR can be an alternative.

- Improved resolution models nested in CMEMS should be developed for the near-coastal areas.

- Same as above
- Tide gauges should be maintained in time and new stations equipped with GPS could be added (but this is very expensive). Baltic Sea Checkpoint combined in situ and model reanalysis data to successfully undertake the Coasts challenge.

- Satellite data and models could be an alternative.
- Visibility and accessibility of the datasets is good, but the coverage is not enough to fulfill the challenges (MPA, Climate).

- These data are needed in several challenges (Wind farm siting, MPA) and in general there is a lack of coverage but also when available, data are too scattered, and difficult to aggregate.

- Same as above: lack of data and too much heterogeneity in the sampling protocols.
- Increase monitoring but, above all, ease access to existing datasets whose access is often restricted (moratorium).

- Same as above

- Same as above
- Availability of river discharge data has recently improved thanks to EMODnet Physics, but at the moment of undertaking the River challenge, most Checkpoints (except Black Sea) identified a lack of coverage and resolution.

- There is a clear gap for this parameter, which is very relevant for Coastal and River Input Challenges. Except for the Black Sea, there are not enough observational data.
- More rivers should be monitored regularly.

- Satellite data (Mediterranean) and models (Baltic) are offered as complementary to improve sediment mass balance estimation in the absence of data. 
Appendix A1 | Continued

\begin{tabular}{lll}
\hline Parameter & GAP & Suggestion \\
\hline $\begin{array}{l}\text { Nutrients (nitrogen, } \\
\text { phosphates) }\end{array}$ & $\begin{array}{l}\text { Very few observations, scattered, low coverage, and } \\
\text { resolution. }\end{array}$ & $\begin{array}{l}\text { - More river inputs should be monitored regularly. } \\
\text { Models could be useful to simulate temperature (Baltic) but } \\
\text { would nevertheless require more observations for validation. }\end{array}$
\end{tabular}

Eels/Salmon

- These variables proved not too relevant for some of the sea-basins (Black Sea, and Arctic). They were sufficient for the smaller basins (North Sea and Baltic), but insufficient in Atlantic and Mediterranean.

River temperature

\section{BATHYMETRY}

Bathymetry and

Elevation
- Same comment than for Nutrients in rivers

- For many of the challenges, aggregated datasets like EMODnet bathymetry are enough. This is the case for Wind farm siting (in some areas), MPAs or Oil platform leak. However, for other challenges that require higher resolution, especially at the coast, less data are available, and they are normally accessible with restrictions (costs, delays) that are country dependent.

- More rivers should be monitored regularly for fish-abundance.

- Same comment than for Nutrients in rivers

- Obviously, a solution to improve resolution would be to increase the sampling, but this is extremely costly. Better metadata would in any case be advisable in order to select the right type of dataset and decide whether it is preferable to opt for a commercial solution in order to save processing time.

- Encouraging lower fees for bathymetric datasets that are within Hydrographic offices would also be desirable.

\section{SEABED/RIVERBED}

Lithology

Sediment balance data

Habitat extent and characteristics
- Much greater resolution would be needed to address challenges like Wind farm siting.

- Data on sediment is clearly insufficient to obtain a basin-scale view of shoreline advance or retreat all over European coasts, and this is highlighted as a priority by the Mediterranean Checkpoint.

- Needed for MPA, Oil spill impact forecasting, and to assess impact of Fisheries on the seabed. In general, their availability and resolution are considered insufficient (with the exception of the UK that has a Marine register database).

\section{HUMAN ACTIVITIES}

Pipelines and cables, Military activities areas, Aquaculture sites, Industrial activities, Leisure activities, Scientific activities...

Maritime traffic data

Fisheries catches/landings

Fisheries bycatch and discards
- Data on human activities were needed for several of the challenges (Wind farm siting, Marine Protected Areas, Oil Platform Leaks). Even though the visibility through EMODnet Human Activities is good, responsiveness is not always fast enough. Also, there are a number of gaps (countries that do not provide data), depending on the variable.

- Vessels tracking data deemed necessary for many challenges (Wind farm siting, MPA, Oil spill, Fisheries Impact, and Alien Species) but they were not downloadable.

- The Data Collection Framework (DCF) obliges the EU Member States to collect this type of data, which are managed by the Joint Research Council (JRC) for scientific purposes. However, with the exception of the Black Sea, most of the Checkpoints detected deficiencies: data were not obtained easily or did not have the right format.

- Data on discards (especially discards in numbers vs. discards in mass) are very scarce and only exist for certain species. When they exist, their quality is doubtful. All Checkpoints (except the Black Sea) coincided in highlighting this problem. Bycatch data are even more difficult to find, in particular for mammals and birds.
- More surveys

- More in situ monitoring and/or combination with satellite monitoring and modeling, monitoring best practices to be established.

- Increase efforts both in new surveys but also in creating aggregated datasets.

- This seems clearly more a question of improving the accessibility than of increased monitoring.

- Another case where the problem lies in the accessibility of the data, and not in a gap in monitoring. EMODnet Human Activities has contributed to fill in this gap with the release of a Vessel Density Map in March 2019.

- Access to data on catches and landings from DCF should improve.

- ICES can be an alternative source of data.

- More monitoring could become part of the DCF to obtain data on discards and bycatch. In the Baltic Sea, bycatch data may improve once a suitable monitoring scheme is agreed upon at the Baltic Sea level. 